\title{
Analysis of Scientific Research Driving Microalgae Market Opportunities in Europe
}

\author{
Judith Rumin ${ }^{1}$, Elodie Nicolau ${ }^{2}$, Raimundo Gonçalves de Oliveira Junior ${ }^{1} \mathbb{D}$, \\ Claudio Fuentes-Grünewald ${ }^{3}$ (D) and Laurent Picot ${ }^{1, *(D)}$ \\ 1 La Rochelle Université, UMRi CNRS 7266 LIENSs, Avenue Crépeau, 17042 La Rochelle, France; \\ judith.rumin@univ-larochelle.fr (J.R.); oliveira.farma.junior@gmail.com (R.G.d.O.J.) \\ 2 IFREMER, Laboratoire BRM/PBA, Rue de l'Ile d'Yeu, 44311 Nantes, France; Elodie.Nicolau@ifremer.fr \\ 3 Department of Biosciences, Swansea University, Singleton Park, Swansea, Wales SA2 8PP, UK; \\ c.fuentesgrunewald@swansea.ac.uk \\ * Correspondence: laurent.picot@univ-lr.fr; Tel.: +33-5-46-45-82-20; Fax: +33-5-46-45-82-65
}

Received: 28 April 2020; Accepted: 14 May 2020; Published: 18 May 2020

\begin{abstract}
A bibliographic database of scientific papers published by authors affiliated to research institutions worldwide, especially focused in Europe and in the European Atlantic Area, and containing the keywords "microalga(e)" or "phytoplankton" was built. A corpus of 79,020 publications was obtained and analyzed using the Orbit Intellixir software to characterize the research trends related to microalgae markets, markets opportunities and technologies that could have important impacts on markets evolution. Six major markets opportunities, the production of biofuels, bioplastics, biofertilizers, nutraceuticals, pharmaceuticals and cosmetics, and two fast-evolving technological domains driving markets evolution, microalgae harvesting and extraction technologies and production of genetically modified (GM-)microalgae, were highlighted. We here present an advanced analysis of these research domains to give an updated overview of scientific concepts driving microalgae markets.
\end{abstract}

Keywords: bibliometric; microalgae; biofertilizers; bioplastics; biotechnology; cosmetics; Europe; food; GMO; market; nutraceuticals; pharmaceuticals; research

\section{Introduction}

The use of microalgae biomass as an alternative and innovative source to produce food, feed ingredients, cosmetics, biopharmaceuticals, nutraceuticals and renewable energy has been well established and documented [1-9]. With an estimated number of 30,000-1,000,000 species, microalgae represent an exceptional natural resource to explore for the 21st century that combines numerous advantages, such as original metabolisms and chemical compositions, fast growth, high photosynthetic efficiency, non-competition for farmlands and tolerance to wastewaters during cultivation. However, despite these major advantages, scientific, technological, legislative, administrative and marketing gaps are barriers still exist that limit the commercial development of microalgae and microalgae-related products. In December 2018, as part of the Interreg EnhanceMicroalgae EAPA 338_2016 project [10], a workshop was organized in la Rochelle, France, to discuss and identify with 12 European microalgae experts the market opportunities arising from European research on microalgae and cyanobacteria, and define gaps and barriers limiting the industrial and markets developments. These European microalgae experts were selected as a representative panel of researchers and industrials with a high knowledge and experience in microalgae field, technologies and markets.

The first statement was that Europe presents a high potential for microalgae research, innovation and industrial development, bringing together a critical number of expert researchers, companies and technological platforms. Accordingly, a bibliometric analysis of microalgae research revealed that the 
European scientific community published 26,137 papers in the field of microalgae and phytoplankton until 2019 [11]. (This bibliometric analysis used 26,137 European references available in Scopus, these references are available on demand to the corresponding author.) Most of the papers of that analysis were focused on the function of microalgae in the environment $(8,962$ publications) and their possible use to produce food and chemicals ( 4275 and 4271 publications, respectively). Going deeper into the research topics analysis, papers were found to mainly focus on pigments (1861), proteins (1847), feed (1818), drug (1474), biofuel (1014) and biotechnologies (892), but also on recent niche markets in the fields of biostimulants (13), bioplastics (14), vaccines (16), biofertilizers (22) and nanotechnology (59) [11]. Accordingly, European experts highlighted six major market opportunities for microalgae: the production of bioplastics, biofertilizers, nutraceuticals, pharmaceuticals, cosmetics and biofuels. Two research and development sectors in link with industrial technologies were also emphasized as driving the microalgae markets evolution: the transformation of microalgae to obtain genetically modified (GM-)strains and microalgae harvesting and extraction technologies to improve production yields and add value to microalgae-related products.

In this paper, we propose an advanced analysis of European scientific publications to highlight research trends driving microalgae markets, characterize markets opportunities for microalgae and identify emerging microalgae markets in Europe. The main research concepts, concept networks, emerging concepts and volume of publications over years for major markets and related technologies are detailed. This work complements an in-depth global analysis of microalgae research in the world, Europe and the European Atlantic Area, recently published in this journal [11].

\section{Results}

\subsection{Technological Research Driving Microalgae Markets}

\subsubsection{Genetically Modified Microalgae (GM-Microalgae)}

Technical advances in the genetic manipulation of microorganisms and genome sequencing of microalgae have stimulated the development and use of GM-microalgae for biotechnological applications [12]. This emerging research domain, with strong ethical and regulatory framework, is mostly dedicated to the production of GM-strains producing high added value compounds for health or biotechnological applications such as recombinant proteins (vaccines and hormones) or biofuel. The production of GM-strains, which requires a strictly controlled environment complying with European regulations [13], is completed with mutations-selection strategies to generate strains with desirable commercial traits such as tolerance to excess light and heat stress, resistance to herbivore/pathogen, capacity to outcompete opportunistic organisms or to overexpress biosynthetic pathways [12]. Publications studying or reviewing GM-microalgae are regularly produced in Europe. Figure 1 highlights the main concepts and concepts networks arising from these papers. Microalgae transformation using genetic engineering has generated interest since 1981 but did not drive more than four publications/year in Europe until 2017. Following 2017, a faster development of domesticated strains and acceleration of genome sequencing led to more than 20 publications/year (Figure 1). France, Germany and Spain were the main countries publishing in this field with 52, 44 and 36 publications, respectively (Figure 10a). The main concepts emerging from this European database on GM-microalgae were microalgae, transformation and genetic. These concepts are linked to the productivity of microalgae molecules and are very connected, as shown in Figure 1. This figure also highlights strategies to improve a character of interest (high growth rate, overaccumulation, deficiency, fitness, survival, deficient, stress and light intensity). The increase in yield of molecules of interest targets hydrogen/hydrogenase, starch, amino acid, acid or resistance to biotic or abiotic stress. The cluster including lipid and fatty acid is isolated because of the large number of publications aiming at improving the productivity of microalgal strains to produce biofuel. The full realization of this potential in microalgae also requires research and progress in the cultivation and growth techniques either by understanding and increasing the capacity of the photosynthetic apparatus as highlighted in the photosystem, chloroplast, photosynthetic, 
photosynthesis and energy concepts or by optimization of cultivation in photobioreactor to maximize the efficiency of solar energy conversion into biomass and bio-products to achieve a profitable product $[12,14]$. The genetic tools required for these improvements were the genetic manipulation of species (mutation, mutant strains, molecular, resistant mutant and cell), the analysis of metabolic pathways (model, mechanism and metabolic) and genome editing (genome and encode). A large part of the molecular genetic studies was carried out in one specific species whose genomes have been sequenced such as the model green species Chlamydomonas reinhardtii by comparing mutated strains to the wild type. More recently, the concepts that have emerged from this GM-microalgae research domain are acid, concentration, heterologous expression, microorganism, protocol, transformation condition, acid content, Acutodesmus obliquus, acyltransferase, Agrobacterium tumefaciens, biodiesel, biomass, Boraginaceae, Bzip14, cell, carbon and carbon reallocation. The development of new molecular tools such as the CRISPR/Cas9 technology will probably stimulate research, funding and evolution of the regulation to achieve economic viability and support innovative applications in the field of GM-microalgae biotechnology in Europe. It should be noted that all this GM-microalgae work has been done at lab scale and in strictly biosafety GM conditions because of the strict EU regulatory issues on GM species. As far as the authors know, no GM microalgae species has been grown in Europe neither at pilot scale $(<1000 \mathrm{~L}$ in closed system such as photobioreactors) nor at industrial scale.

\subsubsection{Microalgae Harvesting and Extraction}

Despite the potential of high-added value molecules from microalgae, current production costs still constitute a limiting barrier to the microalgae economic viability and introduction to markets in Europe. Technological improvements are thus needed to reach a cost-effective large-scale production of microalgae-based products that could stimulate the creation of a dense microalgae industrial sector. Among these technologies, harvesting and drying of microalgae biomass have been identified as key bottlenecks as they contribute to one third of the final biomass cost [12]. In European papers, it can be shown that microalgae biomass is mostly harvested by chemical coagulation/flocculation, auto and bioflocculation, gravity sedimentation, flotation, electrical base processes, filtration and centrifugation [15]. In our database, 175 papers dealt with microalgae harvesting processes and the volume of publications was about 20 publications per year since 2012 (Figure 2). The main concepts contained in these publications were harvest, microalgae/microalgal, biomass, cell, concentration, energy, algal/algae, growth, cultivation, flocculation, extraction, lipid and model. The flocculation cluster in green, linked to Chlorella vulgaris and low-cost concepts, highlights the dominance of this harvesting method in recent years. Among the most cited publications, harvesting methods studied were flocculation, bio-flocculation, electro-coagulation-flocculation and microfiltration membranes (Table 1). The main country publishing on microalgae harvesting was Spain with a total of 52 publications, followed by Italy, Belgium, Germany and France with 22, 20, 20 and 20 publications, respectively (Table 2). Emerging concepts identified in the two last years on microalgae harvesting publications are presented in Table 3 . No innovative concepts emerge from this list, but a large part of studies deal with the assessment of new flocculants such as chitosan (Figure 2), aluminum chloride or copper sulfate [16-20] (Table 3). Additionally, it should be noted that innovative microfluidics harvesting systems are developed by companies. Many publications discussing microalgae harvesting had a link with the production of lipids, as demonstrated by the connection with the C16 (Palmitic acid) and C18 (Stearic acid) emerging concepts. 


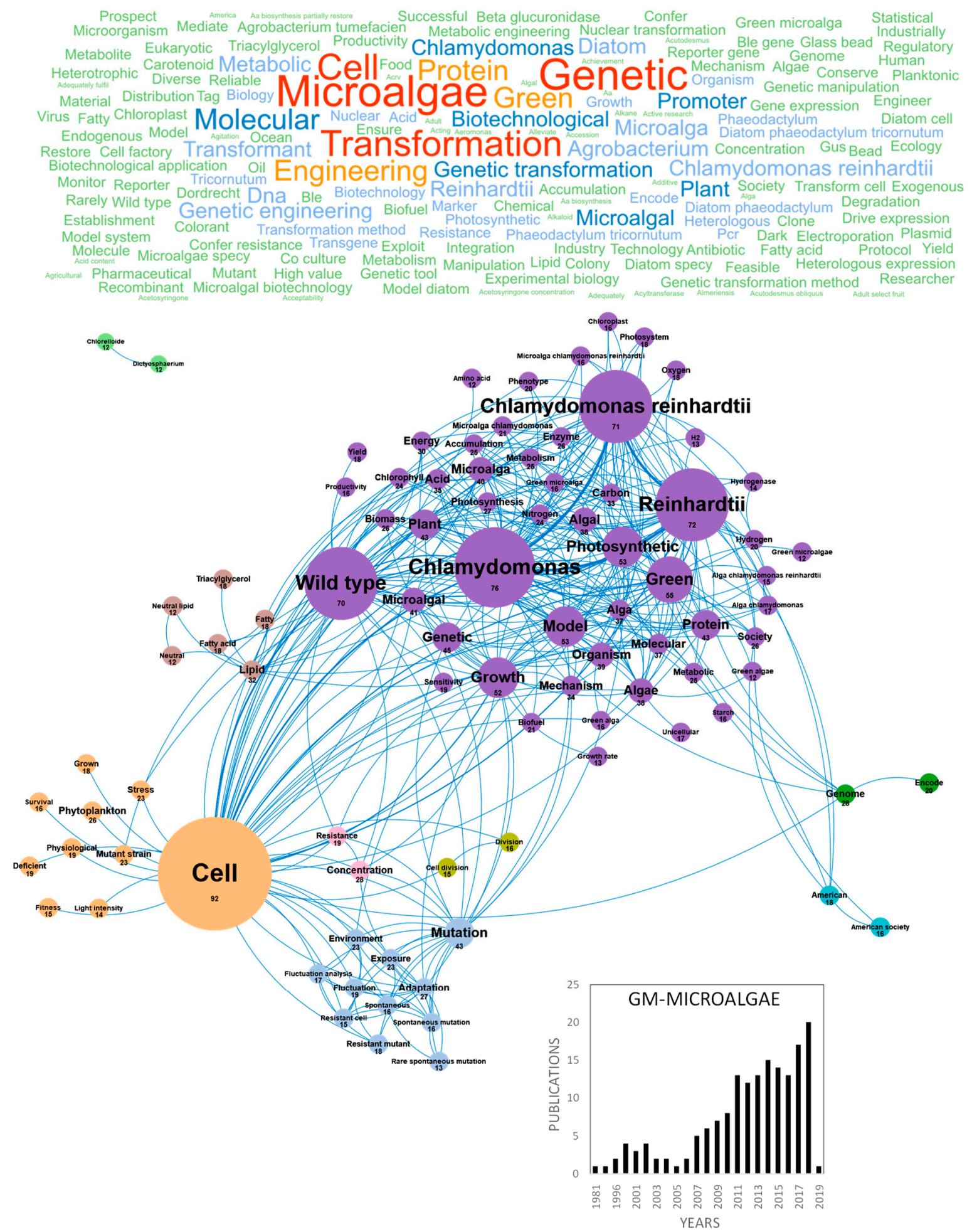

Figure 1. Main concepts, concepts network and annual number of European scientific publications related to genetically modified microalgae (GM-microalgae) in 166 publications (400 links; 28 coocc; 12 occ; and 9 clusters). 


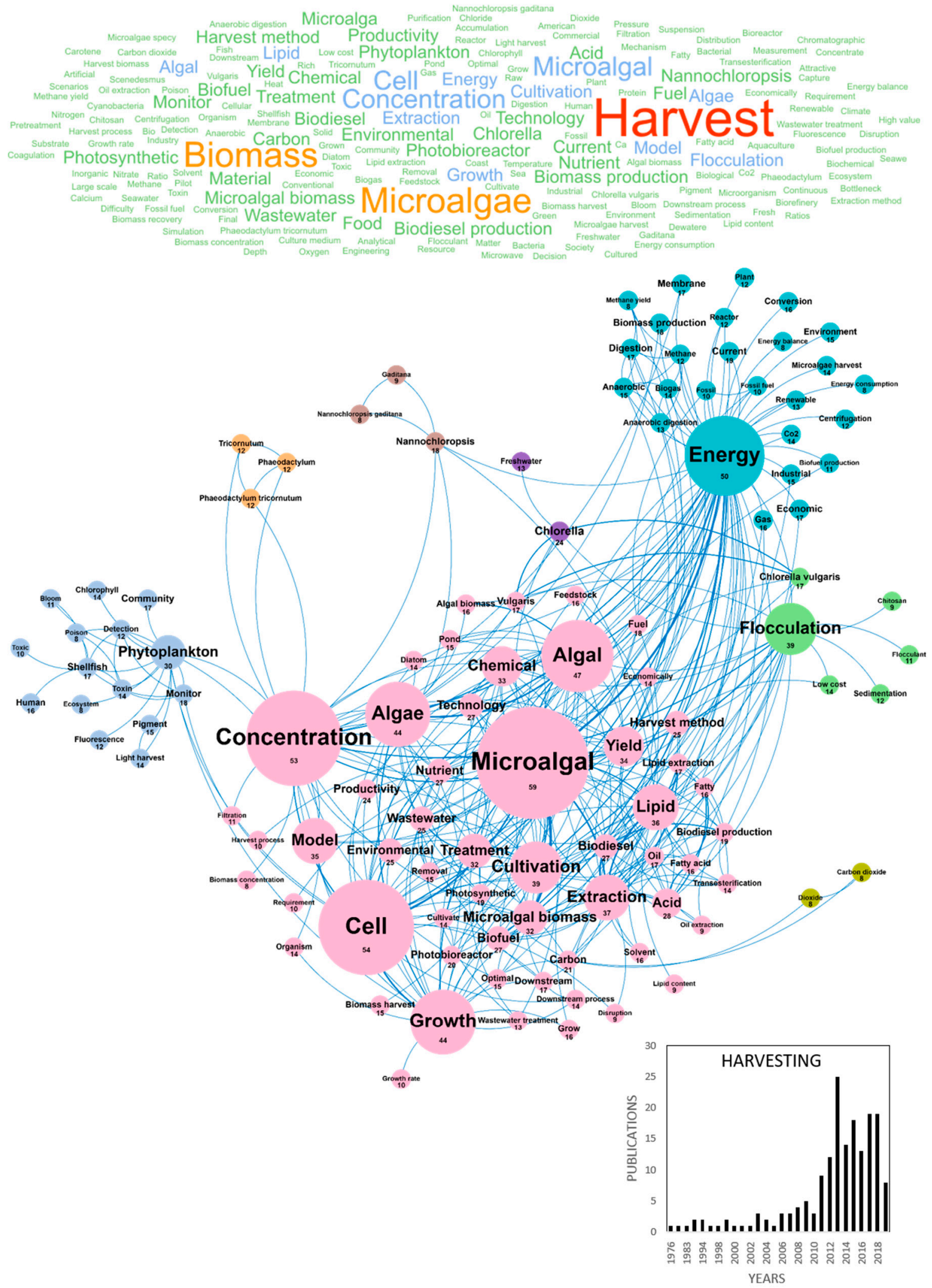

Figure 2. Main concepts, concepts network and annual number of European scientific publications related to the microalgae harvesting in 175 publications (400 links; 7 coocc; 8 occ; and 8 clusters). 
Table 1. Main publications cited in Europe in the domain of microalgae harvesting.

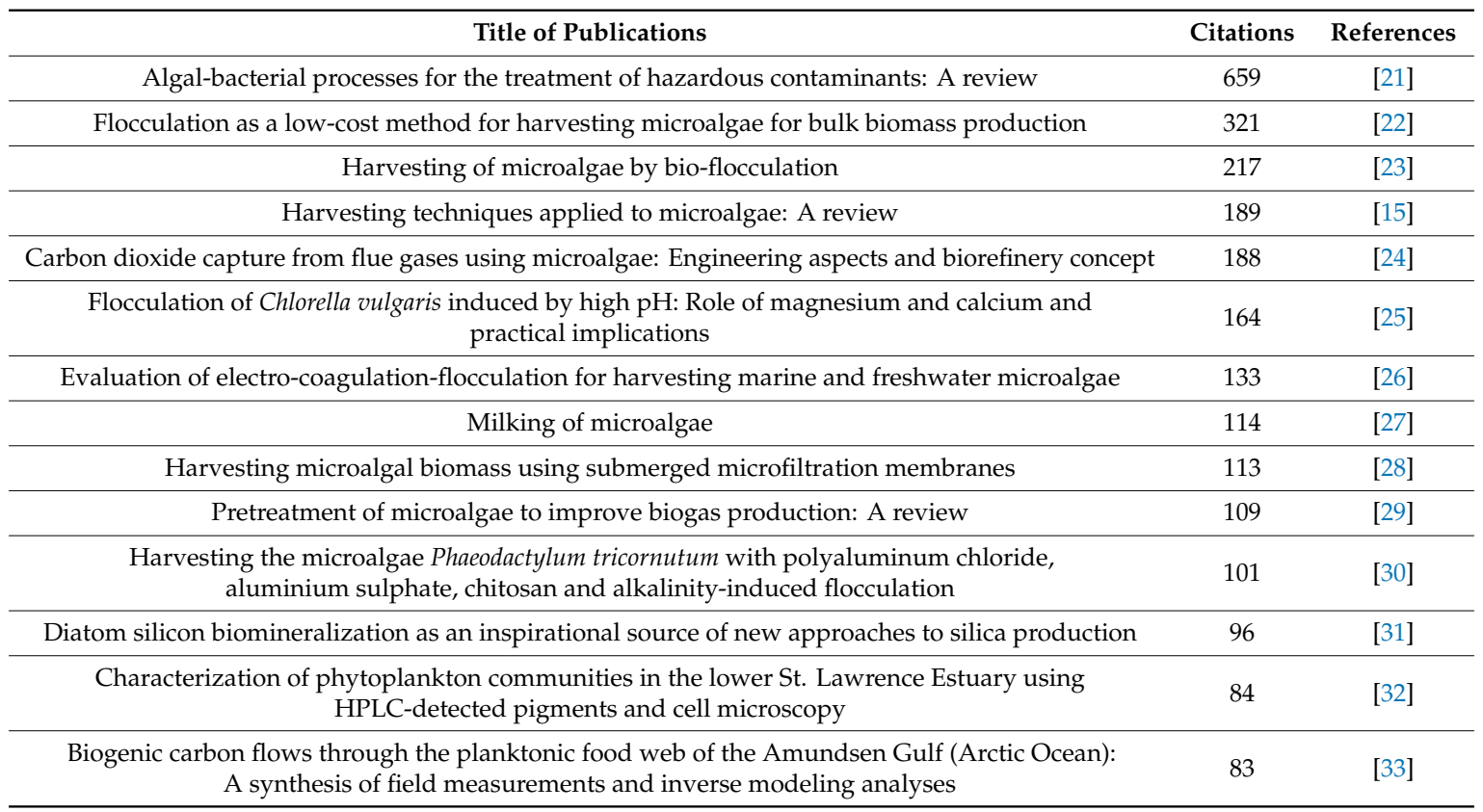

Table 2. Top 15 countries publishing on the topic of microalgae harvesting in the European database.

\begin{tabular}{cc}
\hline Countries & Publications \\
\hline Spain & 52 \\
Italy & 22 \\
Belgium & 20 \\
Germany & 20 \\
France & 16 \\
Portugal & 13 \\
United States & 13 \\
Netherlands & 12 \\
Sweden & 7 \\
Australia & 6 \\
Canada & 6 \\
Denmark & 6 \\
United Kingdom & 6 \\
Austria & 5 \\
Chile & 5 \\
\hline
\end{tabular}

Table 3. Top 13 emerging concepts during 2017-2019 and growth factors (GF) identified in the microalgae scientific publications in the harvest European database.

\begin{tabular}{cc}
\hline Emerging Concepts & GF \\
\hline Asian & 3 \\
Incubation & 3 \\
Mitigate & 3 \\
Robust & 3 \\
Stock & 3 \\
Adhere & 2 \\
Agriculture & 2 \\
Aluminum sulfate & 2 \\
Artificial breed & 2 \\
Artificial substrate & 2 \\
Asian market & 2 \\
Benthic community & 2 \\
Blend & 2 \\
Breed & 2 \\
C16 & 2 \\
C18 & 2 \\
Commercial scale & 2 \\
Continental & 2 \\
Copper & 2 \\
Driven & 2 \\
\hline
\end{tabular}


Improving the production of high-added value molecules from microalgae and reaching a cost-effective production also depend on developing innovative extraction processes such as supercritical $\mathrm{CO}_{2}$ extraction, membrane micro-ultra-nanofiltration/fractionation or nannobubbles technology [34]. In our database, 427 publications studied this challenge, with a production of about 25 publications per year since 2012 reaching 57 publications in 2018 (Figure 3). The main concepts found in these publications were extraction, microalgae/microalgal, cell, biomass, acid, solvent, lipid, yield, chemical, concentration, phytoplankton, algae/algal, extraction method and fatty acid. Most of these concepts constituted major clusters, dominated by lipid extraction from microalgae with solvents (acid, lipid, lipid extraction, solvent, ethanol, methanol, hexane, transesterification and fatty methyl). However, the supercritical fluid extraction cluster in purple highlights the recent interest for this innovative extraction method. Among the most cited extraction processes were also described ultrasound-assisted extraction, microwaves-assisted extraction and hydrothermal treatment (Table 4). Most publications dealing with microalgae extraction in collaboration with the AA came from Spain with 120 publications, followed by France, Italy and Germany with 88, 63 and 62 publications, respectively (Table 5). Some emerging concepts identified since 2017 about microalgae extraction are listed in Table 6. Beyond limiting downstream processes for an efficient extraction process, the scientific community was mostly interested in optimizing green extraction techniques, using solvents-free, clean, scalable, economic and sustainable extracting processes (Figure 3) (Table 4) [35,36].

Table 4. Main publications cited in the microalgae field in Europe related to the extraction.

\begin{tabular}{|c|c|c|}
\hline Title of Publications & Citations & References \\
\hline $\begin{array}{l}\text { Effect of temperature and nitrogen concentration on the growth and lipid content } \\
\text { of Nannochloropsis oculata and Chlorella vulgaris for biodiesel production }\end{array}$ & 647 & [37] \\
\hline $\begin{array}{l}\text { Improved extraction of vegetable oils under high-intensity ultrasound } \\
\text { and/or microwaves }\end{array}$ & 303 & [38] \\
\hline $\begin{array}{l}\text { Hydrothermal treatment (HTT) of microalgae: Evaluation of the process as } \\
\text { conversion method in an algae biorefinery concept }\end{array}$ & 236 & [39] \\
\hline Harvesting of microalgae by bio-flocculation & 217 & [23] \\
\hline Innovative natural functional ingredients from microalgae & 190 & [40] \\
\hline Screening for bioactive compounds from algae & 183 & [41] \\
\hline Downstream processing of algal polyunsaturated fatty acids & 158 & [42] \\
\hline $\begin{array}{l}\text { An economic, sustainability, and energetic model of biodiesel production } \\
\text { from microalgae }\end{array}$ & 152 & [36] \\
\hline Biotechnological production of lutein and its applications & 151 & [43] \\
\hline $\begin{array}{l}\text { Optimization of accelerated solvent extraction of antioxidants from } \\
\text { Spirulina platensis microalga }\end{array}$ & 144 & [44] \\
\hline Lipid extraction from the microalga Phaeodactylum tricornutum & 131 & [45] \\
\hline $\begin{array}{l}\text { Freshwater phytoplankton quantification by chlorophyll a: A comparative study of } \\
\text { in vitro, in vivo and in situ methods }\end{array}$ & 127 & [46] \\
\hline $\begin{array}{c}\text { "Solvent-free" ultrasound-assisted extraction of lipids from fresh microalgae cells: } \\
\text { A green, clean and scalable process }\end{array}$ & 123 & [35] \\
\hline
\end{tabular}




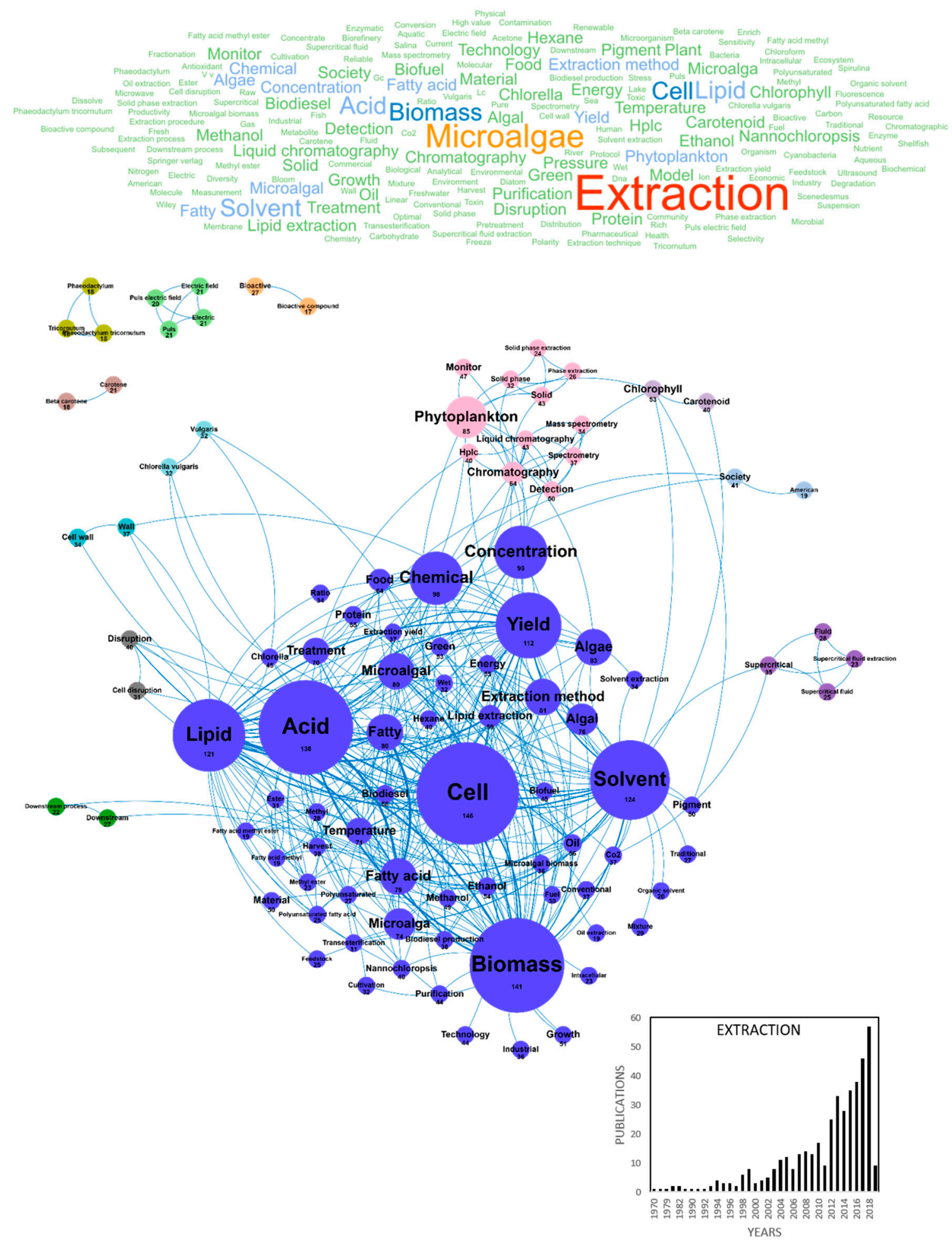

Figure 3. Main concepts, concepts network and annual number of European scientific publications related microalgae extraction in 427 publications (400 links; 17 coocc; 17 occ; and 13 clusters). 
Table 5. Top 15 countries publishing on the topic of microalgae extraction in the European database.

\begin{tabular}{cc}
\hline Countries & Publications \\
\hline Spain & 120 \\
France & 88 \\
Italy & 63 \\
Germany & 62 \\
Netherlands & 37 \\
Portugal & 27 \\
Sweden & 19 \\
United Kingdom & 19 \\
Denmark & 15 \\
Belgium & 14 \\
Poland & 13 \\
United States & 13 \\
Ireland & 10 \\
Brazil & 9 \\
China & 9 \\
\hline
\end{tabular}

Table 6. Top 13 emerging concepts during 2017-2019 and growth factors (GF) identified in the microalgae scientific publications in the extraction European database.

\begin{tabular}{cc}
\hline Emerging Concepts & GF \\
\hline Springer nature & 8 \\
Anthropogenic & 4 \\
Biomolecule & 4 \\
Germany & 4 \\
Np & 4 \\
Prokaryotic & 4 \\
Springer verlag gmbh & 4 \\
Springer verlag gmbh germany & 4 \\
Carotenoid extraction & 3 \\
Enzymatic treatment & 3 \\
Evolve & 3 \\
Figure & 3 \\
Ribosomal & 3 \\
See fulltext & 3 \\
Universal & 3 \\
Ag & 2 \\
Agriculture & 2 \\
Alkyl & 2 \\
Allocation & 2 \\
Barcod & 2 \\
\hline
\end{tabular}

\subsection{Top 6 Market Opportunities for Microalgae Research}

\subsubsection{Microalgae-Based Biofuels}

One of the major concerns of modern societies is the exhaustion of conventional "fossil" resources with the increase of human population, expected to reach a total of 9 billion people by 2050 [47]. Microalgae have received a great deal of interest as potential biofuel producers in response to energy crisis, global warming and climate changes [48]. It is indeed estimated that they could provide up to $25 \%$ of the required energy [15,49]. Ecofriendly, nontoxic microalgae-based oils can be used as raw material for the production of biodiesel, biomethane, bioethanol, biohydrogen and biobutanol, in a sustainable cycle including atmospheric $\mathrm{CO}_{2}$ fixation. The first investigations on microalgal bio-energy started in the 1950s and countries in Asia, Europe and America have now started the industrialization of biofuels production from microalgae biomass [50]. In Europe, 1202 scientific publications related to 
this topic were produced until 2019 and this number should keep on increasing dramatically in the near future as microalgae-based biofuels are still not economically profitable [48]. The challenges to overcome are related to production scalability, operational stability and associated costs compared to other energy sources. Most studies dedicated to the production of biofuels by microalgae focused on improvements of cultivation, harvesting, extraction, biorefinery and conversion methods [51]. In Europe, numerous in-depth reviews of the literature dealt with microalgae-based biofuels and 152 articles containing both the words "review" and "biofuels" were found in our database. Figure 4 shows the word clouds of the main concepts contained in the European scientific publications, networks and clusters established between these concepts and the temporal production of these publications. The scientific production on biofuels increased considerably in the early 2010s from 8 publications/year in 2008 to 143 publications/year in 2013. Since then, the number of papers stabilized with approximately 160 publications per year. Spain, Italy and France were the top three countries publishing in the field of microalgae-based biofuels with around 200 publications (229, 200 and 191, respectively). The main concepts that emerged from this biofuels European database were microalgae, biomass, biofuel, lipid, growth, biodiesel and energy (Figure 4). After dismissing these ubiquitous concepts, 13 clusters could be highlighted. The main cluster in blue characterizes the concepts of the lipid productivity of the cell. One of the major scientific challenge for biofuels (specifically biodiesel) production is indeed to optimize the lipid production yield of microalgae. The efficiency objectives are clearly identified by the productivity, feedstock, production and yields concepts as well as the fatty acid, algal, cell and oil concepts and focused on economic viability of biodiesel production systems (industrial, industry, economic and large-scale). Microalgae contain a rich diversity of carbon compounds that can be transformed into biofuels but lipids are the most promising class of biomolecules, on which efforts have been focused to date, as shown in Figure 4. Most microalgae species are favorable for biodiesel production because of their high lipids contents (50-70\%) and some species such as B. braunii can reach lipids contents up to $80 \%$ [3,52]. Another first line of improvement for the near future is related to the scalability and costs of microalgae cultivation [51]. The aim is to exploit the biodiversity and physiology of microalgae and optimize the culture parameters in photobioreactors for the production and accumulation of biomolecules (lipids, pigments, carbohydrates and hydrocarbons) precursors to biofuels. Biomass production yields highly depend on algae strain, $\mathrm{CO}_{2}$ supply and light regime [53] and it is estimated that microalgae have the potential to transform 9-10\% of solar energy (average sunlight irradiance) into biomass with a theoretical yield of $77 \mathrm{~g} /$ biomass $/ \mathrm{m}^{2} / \mathrm{day}$, corresponding to $280 \mathrm{ton} / \mathrm{ha} /$ year $[54,55]$. However, this yield is lower at larger scale cultivation and in photobioreactors because of light absorption by biomass and culture equipment [56]. Applied research tends to solve the obstacles of light intensity loss by proper shaking and mixing of the culture in the bioreactor, allowing the uniform distribution of light energy and maximum light energy conversion to biomass [50]. Biomass production efficiency also highly depends on nutrients feeding [53]. Only in the last decade, the problem of nutrients demand in industrial microalgae sustainable cultivation became a matter of concern in the scientific community, with a special concern for Nitrogen $(\mathrm{N})$ and Phosphorus $(\mathrm{P})[57,58]$, two nutrients required to achieve significant biomass. As microalgal biomass contains about three times the amount of nutrients present in terrestrial plants, competition among energy, bio-products and food production might be shifted from lands to fertilizers issues [58]. The integration of microalgae cultivation with wastewater treatment in biofuels production is one of the most promising solutions and numerous European publications contain the nutrient, nitrogen, carbon, ratio, phosphorus and removal concepts. Recently, efforts were reported to use municipal, agricultural and industrial wastewater sources to recover these valuable nutrients [59-63] in a logic of nutrient removal and bioremediation. It was reported that $1 \mathrm{~kg}$ of algal biomass can fix $1.83 \mathrm{~kg}$ of $\mathrm{CO}_{2}$ and also that some species could use $\mathrm{SOx}$ and $\mathrm{NOx}$ as nutrient flows along with $\mathrm{CO}_{2}[50,64]$. High nutrient removal efficiencies and high productivities in microalgal biomass, lipid and biodiesel were achieved simultaneously using piggery wastewater to cultivate microalgae in photobioreactors [48]. However, the nutrients bio-availability, their utilization efficiency and possible toxicity need to be carefully assessed [58]. Research also tends to use flue gas point 
sources to maximize carbon capture capacity, while sustaining the stability of algal culture in function of pollutants/nutrients concentrations, temperature and $\mathrm{pH}$ variations. Coupling microalgae culture with flue gases depollution could minimize depollution costs, gases transport and storage costs while producing biomass for biodiesel extraction [51]. These studies highlight the growing interest of Europe for greener and sustainable options to produce biofuels at industrial scale and valorize industrial effluents, evidenced by the environmental, greenhouse gas and green concepts (Figure 4). Metabolic engineering of algae is also an active research domain aiming to identify and control the key molecular and physiological mechanisms involved in the production of biofuel precursors. Metabolic modeling, highlighted by the model concept, could soon become an essential decision support tool to identify the main factors modulating lipids metabolism and explore microalgal growth and productivity using simulation platforms [65]. Most scientific studies on biofuels production were performed with the Chlorella and Nannochloropsis genera and related to the Chlorella, cultivation and ratio concepts while Chlamydomonas sp. was also very studied and associated to the starch accumulation and proof of concept cluster (Figure 4). Beside microalgae cultivation, harvesting the biomass in suspension cultures also participates to the high cost of biofuels production, as highlighted by the extraction and harvest clusters in deep blue (Figure 4). Harvesting process contributes considerably in the overall biomass production cost as it usually accounts for about up to 30\% of the total biomass cost [15]. The challenges in harvesting and extraction of microalgae are mainly related to the energy input, especially for concentrating and drying diluted algae cultures. The major methods currently used include flocculation, centrifugation, filtration, gravity sedimentation, electrophoresis, flotation and combinations of these [51]. The cluster including carbohydrates and proteins is isolated because apart from extracted lipids converted into biodiesel, carbohydrates such as glycogen, starch, agar and cellulose can be converted to fermentable sugars for bioethanol production $[51,66]$. Research in Europe also focuses on the conversion of the microalgae biomass into biomethane and biohydrogen by anaerobic digestion (biogas, biomethane, digestion and anaerobic). As for biodiesel, the development of these biofuels will require effort regarding the cultivation and production of carbohydrate-rich biomass, biomass processing (dewatering and harvesting) and improvement of fermentation yield. The concepts that emerged recently from the microalgae biofuels research domain were biomass cultivate, energy sector, fermentative hydrogen, semi continuous mode, simulation tool, suitable fatty acid, anaerobic co digestion, auxenochlorella, capture carbon, cascade and copper. It should also be noted that some recent works aim to extract lipidic biofuels precursors without destroying algal cells. As a conclusion, after several decades of research, it can be considered that algal biofuels production has reached a high technology readiness level (TRL 6), but that competitivity improvements in microalgae growth techniques, harvesting technologies and genetic engineering [50] are still required to make it commercially viable at high scale. A better valorization by using biorefinery approach of microalgae biomass process in order to have several by-products and an efficient and sustainable coupling of microalgae growth with wastewater treatment should help improve the competitivity of microalgae-based biofuels [48]. 


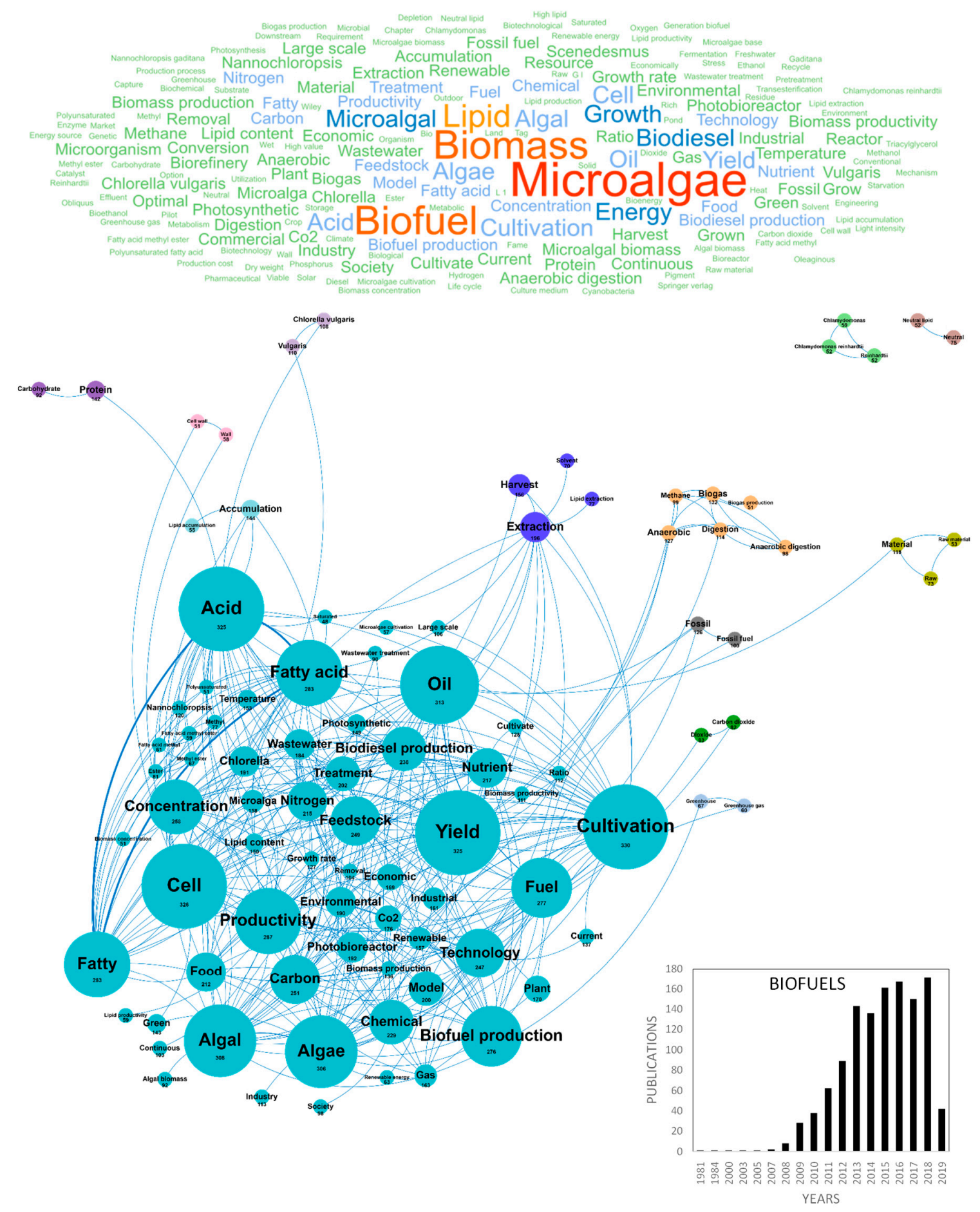

Figure 4. Main concepts, concepts network and annual number of the European scientific publications related to the biofuels field in 1202 publications (400 links; 48 coocc; 48 occ; and 13 clusters).

\subsubsection{Microalgae-Based Bioplastics}

The huge accumulation of plastic waste in the world is driving international demand and stimulating research for the production of renewable and biodegradable plastics [67]. Particularly, the ubiquitous and persistent presence of microplastics in the oceans represents a serious threat for the marine environment, affecting trophic networks from microalgae to superior predators. A direct toxicity of microplastics on microalgae has been demonstrated, even at very low concentrations (in the ppm range) and can be partly explained by their adsorption and aggregation on cells inducing chlorophyll and 
photosynthesis reduction, oxidative stress, morphological changes and growth inhibition, eventually impacting all marine food webs [68,69]. In this context, microalgae biomass is considered an innovative eco-friendly resource for producing bioplastics, mainly using polyhydroxyalkanoates (PHA) as a raw material. It can be used directly or as a feedstock for secondary processes with existing infrastructures and processes [70]. Publications reviewing and studying the different kinds of microalgae-based bioplastics, their chemical properties, their markets and the key barriers limiting their development are currently emerging in the literature. Figure 5 shows the word clouds of the main concepts contained in the European scientific publications, networks and clusters established between these concepts and the temporal production of these publications. Only 3-5 papers were published per year on the topic of bioplastics since 2017 and the number is growing, with three papers already published in the first two months of 2019. Germany and Italy were the main countries publishing microalgae-based bioplastics studies with five and four publications, respectively (Figure 10b). The main concepts emerging from this European database on bioplastics were microalgae, bioplastic, feedstock, biomass and bioplastic production (Figure 5). By dismissing these ubiquitous concepts, a network of 11 differentiated clusters was created. A first descriptive cluster in orange characterizes the eco-friendly advantage of microalgae in the field of bioplastics by bringing together the chemical, plastic, green, biodegradable, renewable and bioeconomy concepts. Publications also highlighted the advantages of bioplastics for industrial application and compatibility with the establishment of a circular bioeconomy which is beginning to develop [67,71]. Among the expanding microalgae circular bioeconomy trend in which companies are also involved for bioplastics, this cluster underlines Europe's current concern for ecology, the need for new greener options for the production of chemicals and polymer materials, combined to the limitation of arable land use, contribution to $\mathrm{CO}_{2}$ capture and waste/byproducts use [71]. A second cluster in green highlights the technical description of concepts related to microalgae cultivation for bioplastics including technology, wastewater, nutrient, treatment and productivity. Nutrient management in microalgae culture to produce bioplastics is a key point linked to the use of wastewater and many studies dedicated to microalgae culture for the production of biofuel also discussed wastewater treatment [62]. The photobioreactor concept highlighted studies dedicated to the physiological orientations of microalgae metabolism to produce bioplastics and made the link with the purple cluster related to starch accumulation in microalgae, containing the cell, starch, cultivation and accumulation concepts. When microalgae cells are placed in stress conditions in the culture medium, particularly in nutrients depletion conditions (nitrogen, sulfur or phosphate), they accumulate biopolymers [72-74] such as polysaccharides, including starch [75,76], lipids [6,77], proteins [78], pigments [79] and other metabolites. Research also aims at giving a proof-of-concept for the production of microalgae-based bioplastics. A recent study has shown that some strains of Chlamydomonas reinhardtii can produce up to $49 \% \mathrm{w} / \mathrm{w}$ of starch in a sulfur-deprived medium and demonstrated the feasibility of up-scaling microalgae starch to small-scale production in $30 \mathrm{~L}$ tubular photobioreactor [80]. The starch-rich biomass presented interesting plasticization capacity and in-depth analysis of conditions and protocols of microalgae plasticization were discussed [61]. Another cluster in grey highlights which microalgae species were studied for the production of bioplastics. Chlorella sorokiniana was the most cultivated species in these studies and the following concepts were dominant: Chlorella, cultivation and ratio. Chlamydomonas sp. was also very studied and associated to the cluster dealing with starch accumulation and proof of concept. An isolated cluster in pink highlights the biorefinery, solar and methane concepts. One way to connect the microalgae biomass feedstock into the existing petrochemical-based plastics industry is to convert biomass to methane through fermentation. A wide range of chemical reactions have thus been developed to further convert methane into precursors for bioplastics production. Methane can be used to produce polyhydroxyalkanoates or PHAs, lactic acid (precursor to polylactic acid or PLA), ethanol (precursor to bio-polyethylene or bio-PE and bio-poly vinyl chloride or bio-PVC) and proteins (precursor to proteins-based polymers). Finally, another cluster could be differentiated around the concepts of acid and fermentation that highlighted the importance of PLA in the current global economy. Polylactic acid (PLA) is a thermoplastic aliphatic polyester derived from renewable biomass and typically obtained 
from fermented plant starch such as corn, cassava, sugarcane or sugar beet pulp. In 2010, PLA was the second most consumed bioplastic in the world. [67]. The emerging concepts associated to the bioplastic database were acid, biorefinery, cultivation, digestion, accumulation, anaerobic, bioeconomy, biorefinery concept, cyanobacteria, driven, driven process, extract starch, fatty acid, human, methane, residue, solar driven process and stabilization. These were the same concepts that appeared in the figure of network concepts because of the youth of this market with one publication per year in 2011, 2012 and 2016 (Figure 5). It can however be noted that emergent research is developed on cyanobacteria, that constitute an immense reservoir of poorly studied species for the production of bioplastics; some examples are from Nostoc genus which produce interesting PHA concentrations. Finally, the authors of these studies stated that the production of durable bioplastics from microalgae for packaging, biomedical or leisure applications may be a long-term challenge [80].

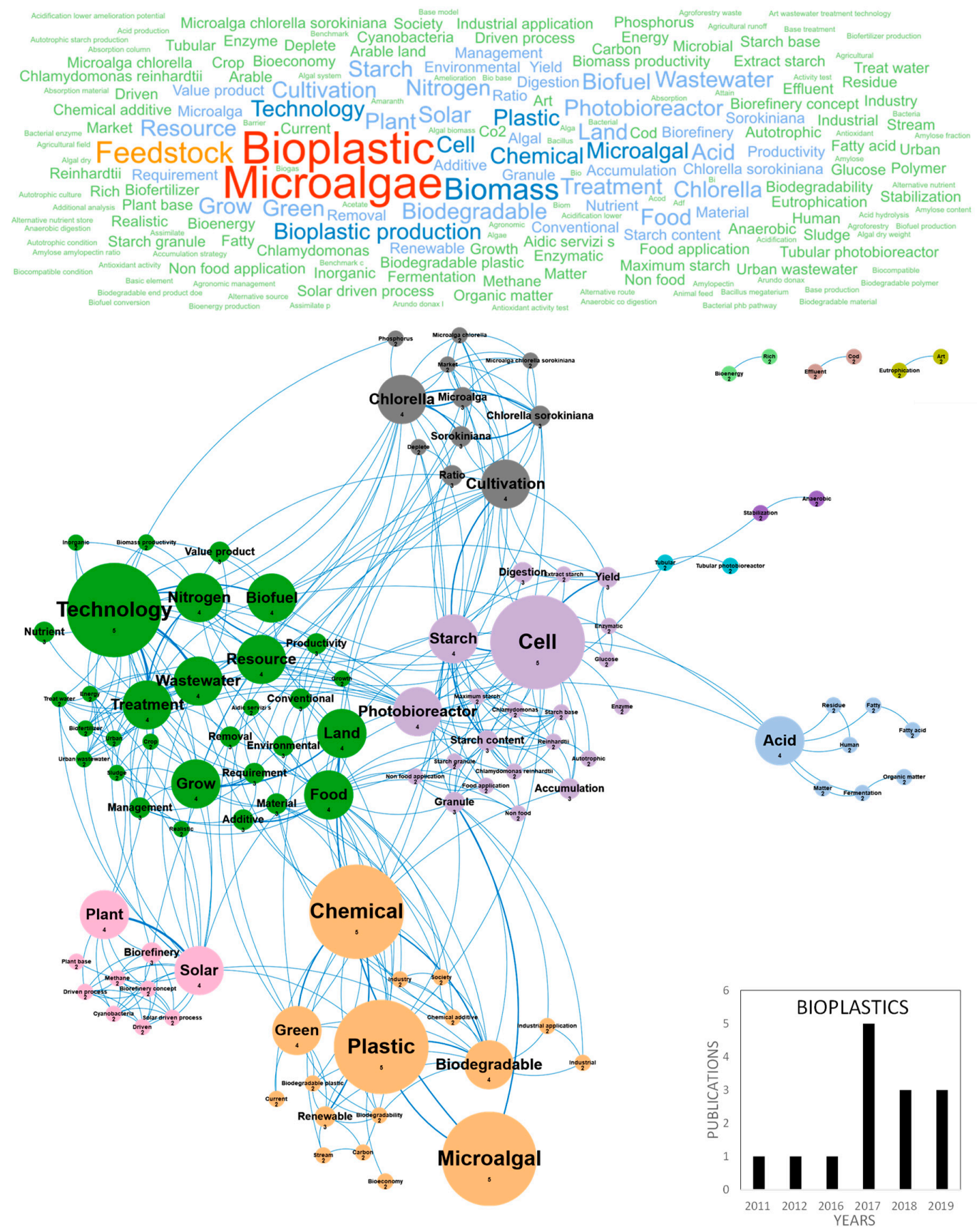

Figure 5. Main concepts, concepts network and annual number of the European scientific publications related to the bioplastic field in 14 publications (400 links; 2 coocc; 22 occ; and 11 clusters). 


\subsubsection{Microalgae-Based Biofertilizers}

The potential of algae-based biofertilizers and biostimulants in agriculture has been increasingly recognized during the recent years. Biofertilizers can provide cost-effective alternatives to synthetic products and renewable and eco-friendly solutions for the future of agriculture. They exhibit a high potential for biostimulation and improvement of crop productivity, improvement of soil fertility and protection against abiotic stresses [81]. The global increase of population and water consumption, the decrease of water supply in some geographic areas, terrestrial and underground water pollution and climate change are currently generating a water crisis that stimulates the research on plant nutrition, wastewater recycling and management of nutrient cycles. In this context, the eco-friendly production of microalgae-based biofertilizers appears as a realistic alternative for the environmental management of wastewater combined to the supply of nutrients for crops [82]. The number of publications that review and study microalgae-based biofertilizers has increased in recent years and the two main countries publishing in this topic were Spain and Italy (Figure 10c). Figure 6 shows the word clouds of the main concepts contained in microalgae scientific publications dealing with biofertilizers, networks and clusters established between these concepts and the temporal production of these publications. The number of publications increased linearly since 2014 reaching nine publications per year in Europe in 2018. The main concepts that emerged from this European database were microalgae, biofertilizer and biomass (Figure 6). After dismissing these ubiquitous concepts, 10 clusters could be highlighted. The nutrient concept in pink, located at the center of the biofertilizer concepts network, is linked to the cluster including productivity, nitrogen, phosphorus, photobioreactor, optimal condition and biofuel. Nitrogen, phosphorus and potassium (NPK) are indeed the top three primary nutrients used as commercial fertilizers [83]. They are also the top three nutrients studied for microalgae growth, to produce microalgae biomass that can be transformed into biofuels or biofertilizers. Nutrient removal yields by microalgae were studied with the aim to achieve an integrated nutrient management (INM) fulfilling environmental regulation. Optimization of microalgae growth conditions to obtain efficient nutrients removals at industrial scale was performed by designing new photobioreactors, such as semi-closed $30 \mathrm{~m}^{3}$ horizontal photobioreactors [82]. The treatment of urban or industrial waste waster by microalgae is an option at industrial scale in USA and Europe and it was also considered from the technological and energetical points of view, in an objective of agricultural valorization, as evidenced by the purple cluster grouping the wastewater, agricultural, urban, technology and energy concepts. Minor clusters such as biogas in orange, including the biogas, reuse and sludge concepts or that of digestion in blue-green including the digestate, digestion and anaerobic concepts, highlight the interest of the microalgae wastewater bioremediation to produce biomass that can be valorized into ethanol, biohydrogen and biogas [71]. Studies were also conducted to identify the microalgae species combining the best bio-remediation and biofertilizing capacities. For example, Chlorella sp. was shown to present high phytostimulating activities on wheat ( $30 \%$ increase in plant length) and proposed as a possible substitute to chemical fertilizers to increase soil fertility [82]. Nannochloropsis sp. was also identified as a sustainable biofertilizer increasing the sugar and carotenoid contents in tomato [84]. The blue cluster containing the Chlorella concept shows that the majority of scientific publications dealing with biofertilizers used Chlorella sp. as a model species [85]. The scientific community was also interested by Acutodesmus sp., Scenedesmus sp., Phaeodactylum sp. and Pavlova lutheri. Biofertilizers studies also focused on microalgae harvesting, as illustrated in the light green cluster including the harvest, substrate and material concepts. The algal biomass is usually harvested during the exponential growth phase to obtain maximum growth yields and a better amino acid profile in order to have an efficient biostimulant activity. The biomass was recovered by centrifugation or filtration and some studies on biofertilizers tested electrocoagulation [82]. Last, the emerging concepts of the biofertilizers database were photobioreactor, carbon, digestate, microalgae biomass, photosynthetic, protein, agriculture, anaerobic, biogas production, carbohydrate, centrate, chemical, culture medium, cyanobacteria, digestion, dilution, matter and maximal nutrient removal. These concepts only represented a maximum of three publications per year until 2016 because of the youth of this research topic but pointed out an interest for the innovative 
use of cyanobacteria as possible biofertilizers. Finally, Win et al. (2018) also pointed out the main limitations in the development of microalgae-based biofertilizers, namely the short shelf life of biomass and need for expensive cold storage [83].

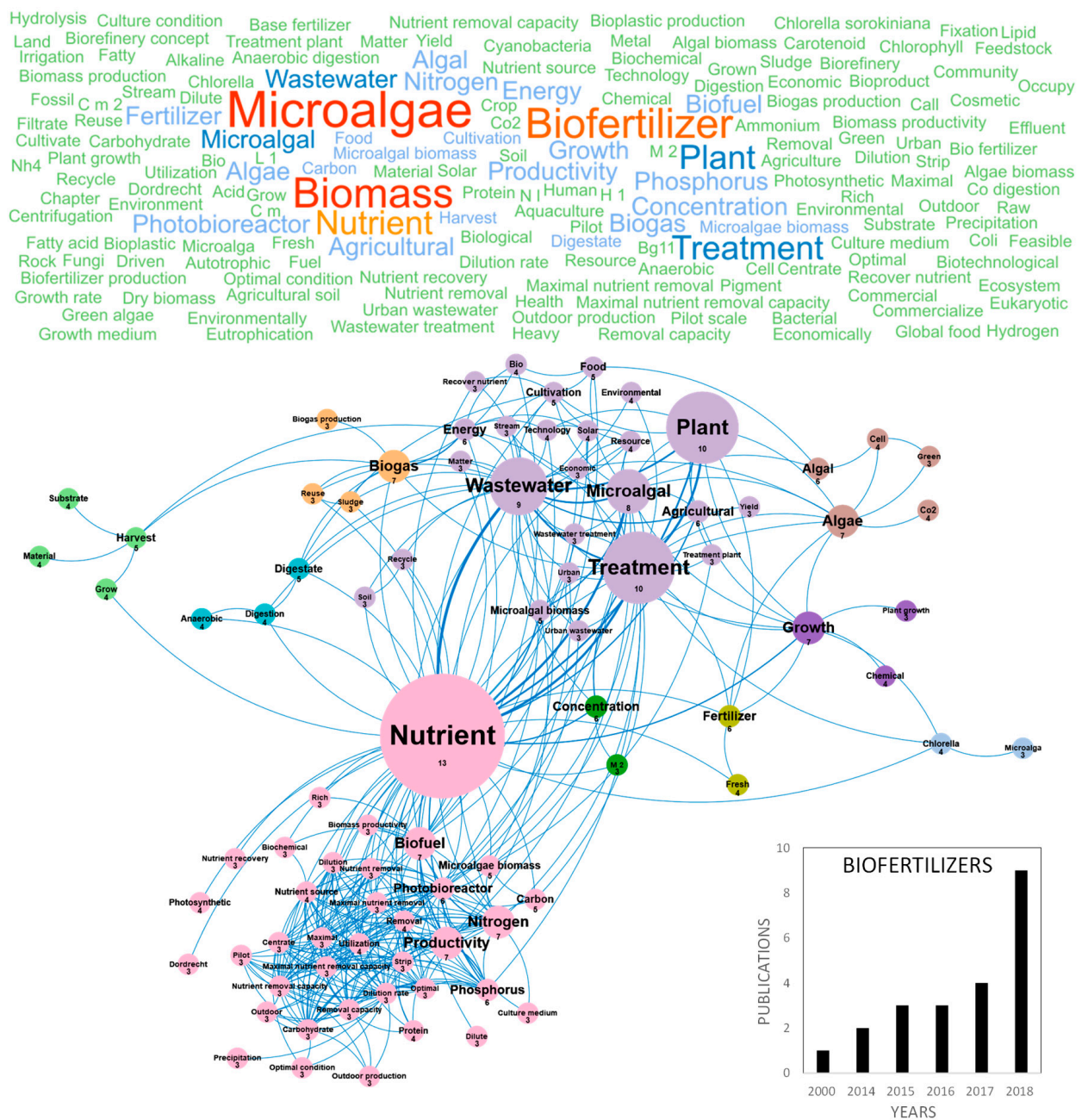

Figure 6. Main concepts, concepts network and annual number of the European scientific publications related to the biofertilizer field in 22 publications (400 links; 3 coocc; 3 occ; and 10 clusters).

\subsubsection{Nutraceuticals}

Microalgae and cyanobacteria have been used as human food for hundreds of years; for example, Aztecs consumed Spirulina (Arthrospira sp.) from Lake Texcoco in Mexico around 1300 AD [86]. Today only few species (GRAS species) have obtained authorization for human food but microalgae and cyanobacteria attract the attention of researchers and consumers because they contain a wide range of nutrients and bio-active compounds, including proteins, polysaccharides, lipids, pigments, polyphenols, minerals and vitamins of high nutritional value. Consumption of whole dried microalgae and cyanobacteria has greatly increased during the last 20 years and they are now considered as an eco-friendly/organic sustainable food, alternative and complementary to "classical" food, with health-promoting properties [86]. More recently, in the 2010s, microalgae- and cyanobacteria-based food supplements or nutraceuticals started to be produced and marketed. Lipids (polyunsaturated fatty acids (PUFAs): EPA and DHA) and pigments (carotenoids) largely dominate these markets. Nutraceuticals can be defined as food nutrients that not only supplement the diet but also facilitate the prevention or treatment of diseases and disorders, according to the producers' claims. Recent papers have reviewed the state of the art about the biotechnological production and use of microalgae [87,88], with a particular focus on their use for food and feed [89-91] or nutraceuticals [92-95]. In Europe, the two 
main countries publishing in the nutraceuticals field were Italy and Spain with 29 and 26 publications, respectively (Figure 10d). Figure 7 shows the word clouds of the main concepts contained in scientific publications dedicated to microalgae nutraceuticals, networks and clusters established between these concepts and the temporal production of these publications. The figure shows that the scientific community interest in microalgae nutraceuticals started in 2013, with about 15 publications/year. The five dominant concepts were nutraceutical, microalgae, food, biomass and acid. These major and ubiquitous concepts were dismissed to obtain a more detailed network of concepts, including nine clusters in Figure 7. The main cluster identified in green is dominated by the antioxidant, antiviral and bioactive compounds concepts and grouped all microalgae molecules and bioactive substances identified as nutraceuticals. Among the nutraceutical supplements or functional food of this cluster, fatty acid, PUFAs, rich and carotenoids overlook widely and their concepts networks are tightly connected. Microalgae constitute natural sources of omega-3 or PUFAs that have unequivocally proved to improve human health and limit diseases (e.g., cardiovascular disorders, cancer, type 2 diabetes, inflammatory bowel disorders, asthma, arthritis, skin disorders, depression and schizophrenia). Due to a clear wild fish capture over exploitation in the last few years and their use as a raw material for oil production (specifically $\omega 3$ oils), purification of PUFAs from microalgae to produce omega-3 capsules has attracted attention since 2013, a time when fish oil and terrestrial vegetables (e.g., flaxseeds) were the only source used to obtain them.

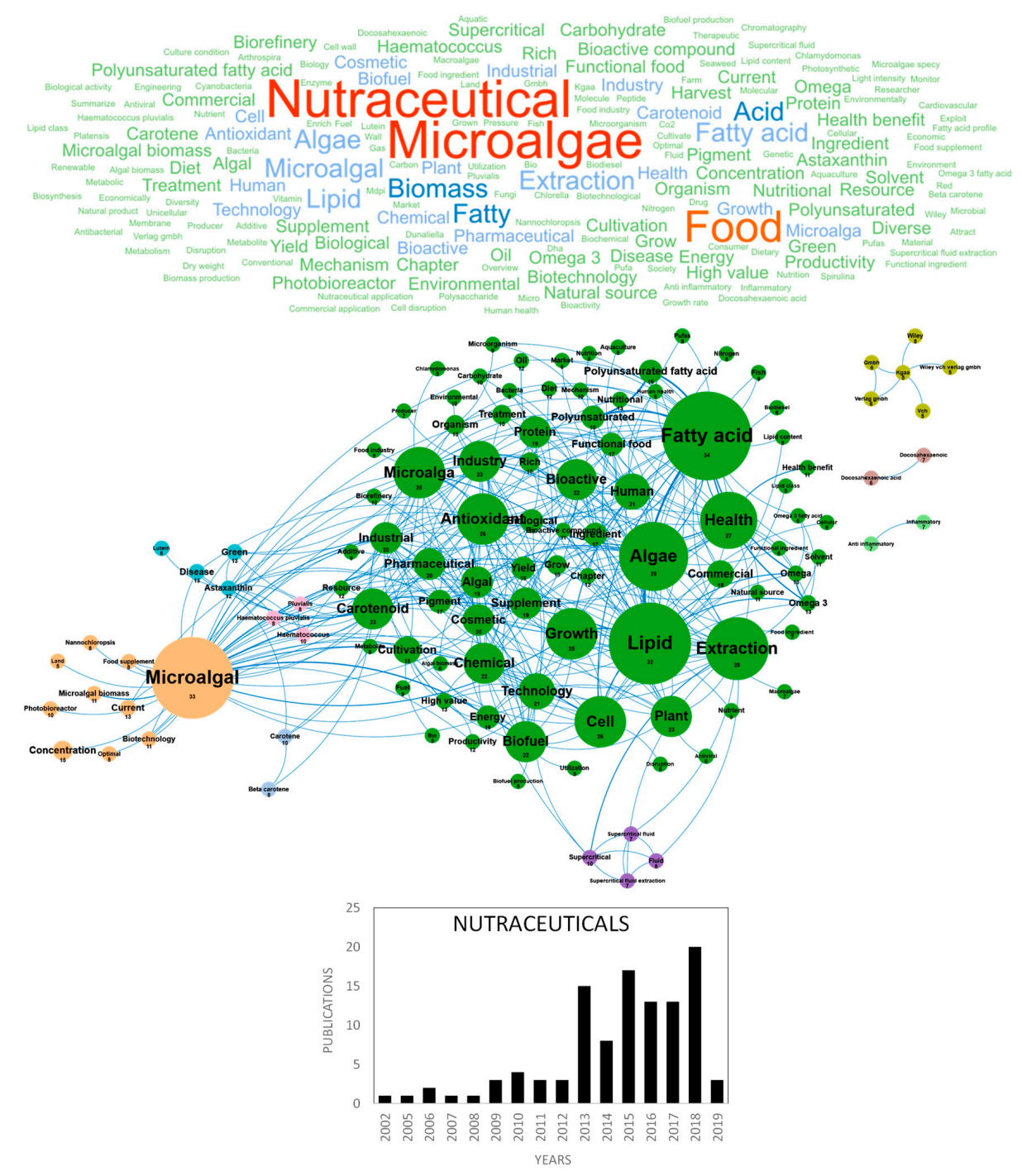

Figure 7. Main concepts, concepts network and annual number of the European scientific publications related to the nutraceutical field in 108 publications (400 links; 5 coocc; 5 occ; and 9 clusters). 
Carotenoids, including $\beta$-carotene, astaxanthin, fucoxanthin, zeaxanthin and lutein are also valorized for a wide range of nutraceutical activities (antioxidant, prevention of DMLA) and functional properties such as food coloring in sweets, salmon, cheese, etc. Carotenoids research is mostly focused on the use of astaxanthin, lutein and green (microalgae) to cure diseases. The two small clusters in pink and blue highlight the niche market of astaxanthin produced by Haematococcus sp. for salmon coloring but Chlorella and Spirulina are dominating the worldwide microalgae nutraceuticals markets because of their popularity as a healthy-food in supermarkets [86]. European researchers have also studied the possible use of carbohydrates as microalgae-based nutraceuticals. Microalgae and cyanobacteria produce various polysaccharides with diversified structures and biological activities that are widely used in the food industry as thickeners and gelling additives. Exopolysaccharides (EPS) production from microalgae is dominated by the red microalgae genus Porphyridium which can be grown in different production systems and at different latitudes [96] and has multiple nutraceutical and pharmaceutical activities such as antioxidant, antitumor, antibacterial and anticoagulant activities $[86,90]$. The aquaculture concept also appeared in this cluster. Indeed, microalgae such as Tetraselmis, Isochrysis, Pavlova, Phaeodactylum, Chaetoceros, Nannochloropsis, Skeletonema and Thalassiosira are commonly used as feed for aquaculture and health-promoting supplements in aquaculture farms, reducing fish larvae mortality, stimulating immunity and limiting the use of antibiotics. Microalgae are also considered today as an interesting nutraceutical feed for ruminants, pigs, poultry and pets. Minor bioactive microalgae compounds were not highlighted in our bibliometric analysis. This may be explained by a low interest for their nutraceutical activity, small or nonexistent markets and low number of publications dealing with their nutraceutical activity. For example, chlorophylls that have demonstrated cell repair activities, antimutagenic, anticarcinogenic and antioxidant activities do not appear in a significant cluster despite their use as colorants by the food industry. The same observation could be made for phycobiliproteins [97], which are already used as natural dyes in food and considered as potent antioxidant, anti-inflammatory, neuroprotective and hepatoprotective pigments. No clusters were also identified for vitamins and sterols. Microalgae sterols [98] have diverse biological functions such as antioxidant, anti-inflammatory, antimicrobial activities and were shown to limit the progression of certain cancers and the risks of cardiovascular diseases, neurodegenerative diseases and diabetes [99]. Volatile and phenolic compounds were also absent from this analysis despite their antimicrobial and anti-inflammatory activities [41]. A cluster linked to recent research on green extraction techniques was identified through the supercritical fluid extraction concept. Two other small clusters highlighted niche research specific to anti-inflammatory drugs and DHA on the right of the word clouds.

From an economic point of view, the industrial orientation of microalgae scientific research towards the potential nutraceutical markets is highlighted by the food industry, industrial, commercial and market concepts. The function of these nutraceuticals is to be incorporated as ingredient, additive or functional ingredient in existing food products. This huge world economic market leads to the global production of 12,000 tons/year of dried Spirulina sp. (with a median price of $30 \mathrm{US} \$ / \mathrm{kg}$ ) followed by Chlorella sp. (5000 tons/year), Dunaliella salina (3000 tons/year), Aphanizomenon flos aquae, Haematococcus pluvalis, Crypthecodinium cohnii and Shizochytrium [86]. From a technical point of view, the scientific research in Europe also focuses on the physiology, optimization and cultivation of microalgae through the microalgal, photobioreactor, microalgae biomass, optimal, current and biotechnology concepts in orange. Nannochlorospis is the model species of this cluster used in nutraceuticals (Figure 7). The scientific publications on nutraceuticals and microalgae are numerous with about a hundred publications related to health, natural sources, bio and human health concepts (Figure 7). The emerging concepts in the nutraceuticals field are focused on Temperature, arable, bar, continuous, fucoxanthin, neutral, physiology, red phase, agricultural, Arthrospira platensis, bench scale reactor, biochemical composition, biomass yield, C18, cholesterol and domesticate strain. Finally, some of these studies mention that the organoleptic properties such as taste, texture, color and odor of this microalgal biomass are potential bottlenecks to markets [86] and identify the cost of developing and obtaining a market authorization for a novel food as a strong barrier limiting the marketing of microalgae nutraceuticals. 


\subsubsection{Pharmaceuticals}

The potential of microalgae molecules for pharmaceutical applications has been extensively reviewed $[100,101]$. The application domains of microalgae metabolites for human and animal health include the prevention and improvement of various diseases including malnutrition, nutritional deficiencies, metabolic syndrome (diabetes, obesity and non-alcoholic steatohepatitis), cardio-vascular diseases, cancer, macular neurodegenerescence, cataract, inflammation, Alzheimer's disease, depression and schizophrenia, fetal malformation, pregnancy complications, auto-immune diseases and dental diseases, as well as bacterial, parasitic and viral infections. Additionally, microalgae represent an innovative biotechnological resource for the production of high-value biomedical products such as recombinant proteins (vaccines, cytokines, hormones), bioactive polysaccharides, lipids or pigments (carotenoids, phycobiliproteins), which can be useful for the treatment, diagnosis and prevention of diseases. Microalgae have also attracted considerable interest to develop pro-cicatrizant extracts (wound healing properties), blood circulation-stimulating extracts, photosensitive pigments for phototherapy, biomaterials and biopolymers [102]. Most studies have only used in vitro assays to demonstrate the pharmaceutical potential of microalgae extracts and purified compounds, but the validation of these activities with in vivo models has become a major objective during the last five years. Following the sharp rise of scientific publications in the nutraceuticals and cosmetics fields, pharmaceutical research on microalgae has been considerably expanding since the early 2010s and the number of technical publications and reviews in this topic has now reached 239. Figure 8 shows the word clouds of the main concepts contained in the scientific publications on pharmaceuticals, networks and clusters established between these concepts and the temporal production of these publications. When the three most important concepts, pharmaceutical, microalgae and biomass, were dismissed from the concept network graph, a network of 14 clusters was created. The main cluster in gray highlights the interconnection of pharmaceutical concepts with the close concepts of food and biomass that dominate the market and nutraceutical, nutritional and cosmetic. Many molecules can be classified as nutraceuticals but the concept of drug establishes a clear link with the pharmaceutical domain. Within this cluster, pigments and PUFAS are highly studied for their pharmaceutical activities. PUFAs have been studied for their potential to prevent and improve cardiovascular disorders, cancer (anti-metastatic activity, antiangiogenic activity and chemo- and radiosensitization of tumor cells), type 2 diabetes, inflammatory bowel disorders, asthma, arthritis, skin disorders, depression and schizophrenia. Pigments and especially carotenoids have demonstrated important pharmacological activities, to improve fertility (astaxanthin), prevent macular degeneration (lutein and zeaxanthin), rheumatoid arthritis, cardiovascular diseases, neurodegenerative diseases, obesity (fucoxanthin) and cancers ( $\beta$-Carotene, fucoxanthin, zeaxanthin, violaxanthin, lutein, alloxanthin, etc.). Because of their use as fluorescents probes in flow cytometry and microscopy and for their use in antibody conjugation methods, phycobiliproteins have generated important research and markets for medical diagnosis, in addition to their use in the food and cosmetic industries as natural dyes [103]. The phycobiliproteins production from microalgae using new methods is led by Porphyridium purpureum in the case of Phycoerythrin and by Spirulina for Phycocyanin production [104,105]. A specific interest was dedicated to the risk associated to microalgae toxins for human health, as illustrated by the pink and purple clusters through the concentration, risk, toxic, aquatic environment and environment concepts. Toxins are pharmacologically active compounds synthesized by microalgae (especially dinoflagellates and diatoms) and cyanobacteria, with deleterious effects for human health. Some toxins have gained importance as pharmacological tools, and could be useful to design new bioactive compounds [106]. Most studies dealing with pharmaceutical activities of microalgae molecules were carried out on Chlorella sp. and Pseudokiclorella sp. as shown in the orange cluster. In this cloud of pharmaceutical concepts, some small clusters can be differentiated. The high value product in blue, the biological activity in light blue, the bioactive compounds and molecules in purple, the anti-inflammatory properties in green can be considered as target concepts. This domain is also strongly associated with the economic and commercial objectives of the pharmaceutical industry that drives the industrial development of microalgae-based 
pharmaceuticals. Pharmaceuticals from microalgae have attracted the interest of researchers for many years as shown in Figure 8. Fewer than 10 publications/year were produced in the field before 2009, then 10-20 publications/year between 2009 and 2014 and more than 35 publications/year since 2015 (Figure 8). Within these 239 publications, the emerging concepts of the last three years show the trend of the research and targeted market. Drugs are among the emerging concepts and in particular anti-depressant and anxiolytic drugs (amitriptyline, Clomipramine and behavior). Other emergent microalgae-based pharmaceutical concepts are culture collection, industrial production, long term, methyl, stream, urban wastewater, additivity, algal treatment, alteration, amitriptyline, basel, behavior, bioactive component, bubble column pbr, catalytic, classification, clomipramine and collection strain.

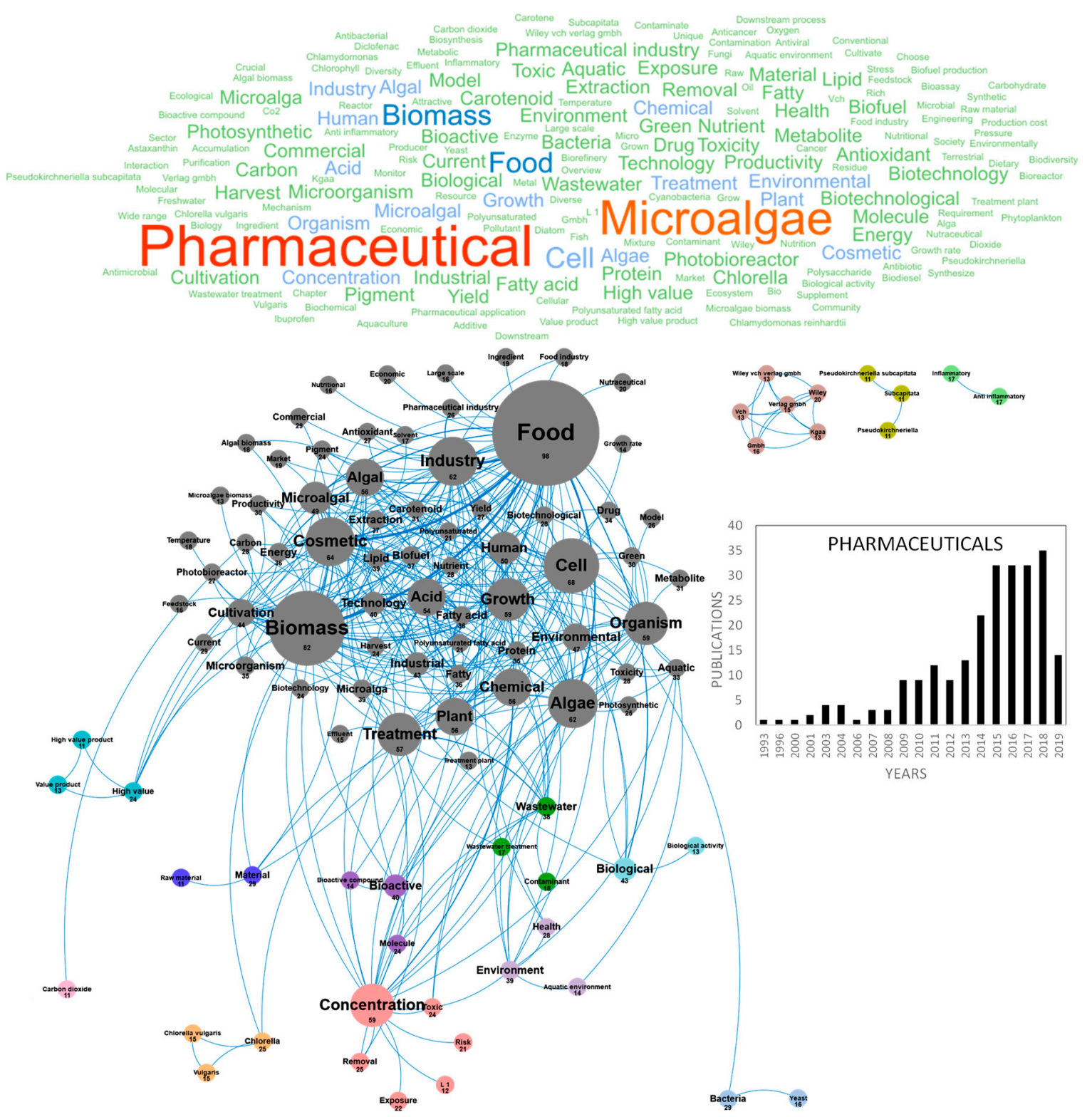

Figure 8. Main concepts, concepts network and annual number of the European scientific publications related to the pharmaceutic field in 239 publications (400 links; 11 coocc; 11 occ; and 14 clusters).

\subsubsection{Cosmetics}

The current production of algae extracts for cosmetics is largely dominated by seaweeds and the use of microalgae was relatively confidential until the 2010s, when the societal demand for skin care and well-being treatments started to grow significantly. In response to these new markets, researchers and 
industrials developed relevant screening in vitro tests, assessed original microalgae species to propose innovative extracts to consumers and started to demonstrate their effective activities to improve the structure, morphology, appearance and health of the skin [107]. The market size for microalgae-based cosmetics is expected to grow significantly in the foreseeable future, because microalgae bioactive extracts are considered as relatively new and innovative as compared with seaweeds ones, and also because microalgae and cyanobacteria biodiversity is huge, offering a wide range of unexploited pigments, polysaccharides, polyphenols, with effective "cosmeceutic" activities. At the frontier between cosmetics and pharmaceutics, cosmeceutics can be defined as "cosmetic products with biologically active ingredients claiming medical or drug-like benefits" [107]. These include biological activities such as antioxidant, anti-aging, sunscreen and UV protective, immune protective, stress protective, moisturizing and texturizing, tanning, make-up (eyeshadows) and masking odors, whitening, stimulating blood circulation and cicatrizating. Publications reviewing and studying cosmetics from microalgae have been published since 1990, but the topic was very confidential with only one publication per year produced in Europe until 2010. A high inflection was observed in 2015, when the number of publications reached about 25 publications per year (Figure 9). The top publishers in the field were France, Spain, Germany and Italy with 24-32 papers published (Figure 10e). Figure 9 shows the word clouds of concepts contained in these scientific publications, networks and clusters established between these concepts and the temporal production of these publications. The main concepts that emerged from this cosmetic European database were cosmetic, microalgae and food. By dismissing these ubiquitous concepts, a network of 12 clusters was highlighted in the 154 publications. The cosmetics market was closely linked to the pharmaceutical application. The main cluster in blue is indeed dominated by the pharmaceutical concept (Figure 9). The research for antioxidant or anti-inflammatory activities is at the heart of the nutraceutical research and cosmetic markets. A focus is made on the potential of bioactive compounds from microalgae and their potential uses in cosmetics mainly in the treatment of skin problems such as aging, tanning and pigment disorders [107]. These authors listed the biological activities of microalgae and cyanobacteria in cosmetics and confirmed that most studies deal with the antioxidant and anti-inflammatory potential of microalgae extracts and molecules [107]. These cosmeceutical bioactive compounds were essentially pigments but also carbohydrates and fatty acids. Among the 154 European publications, the concepts pigment, carotenoid, astaxanthin, chlorophyll and beta carotene highlight the predominance of pigments in European studies.

Carotenoids from microalgae and cyanobacteria have demonstrated a wide range of cosmetics and cosmeceutic activities, including antioxidant, photoprotection, anti-inflammatory and anti-allergenic properties for skin [108]. Pigments were also studied for the production of natural colorants for beauty cosmetics (lipsticks with phycocyanin for eye shadows [109], tanning cosmetics containing canthaxanthin [110], eye liners, etc. Proteins and carbohydrates were also widely studied in cosmetics publications for their potential use as ingredients and texturizing agents. Polysaccharides have mostly been used as excipients (thickeners) and for their moisturizing actives [111]. Some methanolic extracts of exopolysaccharides were also studied for their antioxidant properties [112] and exopolysaccharides produced by Parachlorella improved the health and appearance of skin. EPS from microalgae has been used in commercial cosmetic products since years ago, e.g., Alguard $($ face cream. Current studies are focusing on their possible use in cicatrizing creams and antiviral creams. Last, microalgae lipids have been studied for skin and hair nutrition in shampoos. The applications of microalgae in cosmetic products have recently gained more attention and recent researches are focusing on original bioactives such as lycopene $[113,114]$, canthaxanthin [110], phytohormones $[115,116]$ and mycosporine-like amino acids as renewable bio-sourced UV filters [117]. Innovative applications are also searched for specific markets such as thalassotherapy [107] and thermal cures. No microalgae species were predominant in the European database but the skincare market was dominated by Chlorella, Arthrospira, Nannochloropsis, Porphyridium, Nostoc and Dunaliella for their potential for preventing skin aging, protecting against UV light damage, and oxidative stress [107]. From an economic point of view, this cosmetics market has a very strong link with manufacturers. The industry, industrial, application 
and temperature concepts are highlighted and patents are numerous, both for cosmeceutic applications and customized microalgae culture systems allowing the safe and stable on-site production of original microalgae and extracts [107]. To finish, the emerging concepts of this cosmeceutics database were identified as $g$ dry weight, red phase, acid production, aggregate, bar, behalf, bench scale reactor, bioactive component, compound synthesize, cultivation condition, deal, economy, extraction procedure, fermentation process and Fourier transform.

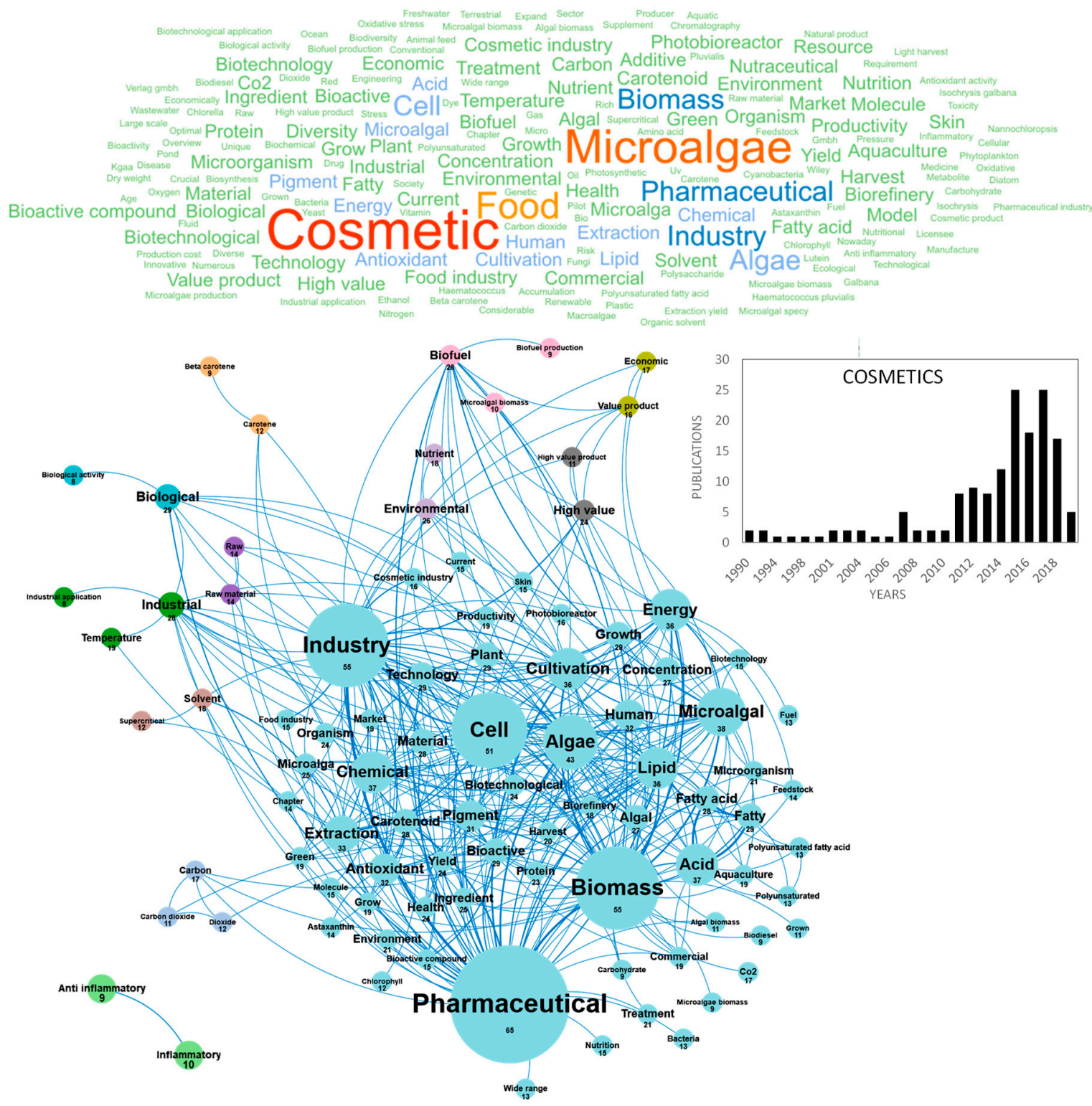

Figure 9. Main concepts, concepts network and annual number of the European scientific publications related to the cosmetic field in 154 publications ( 300 links; 8 coocc; 8 occ; and 12 clusters). 

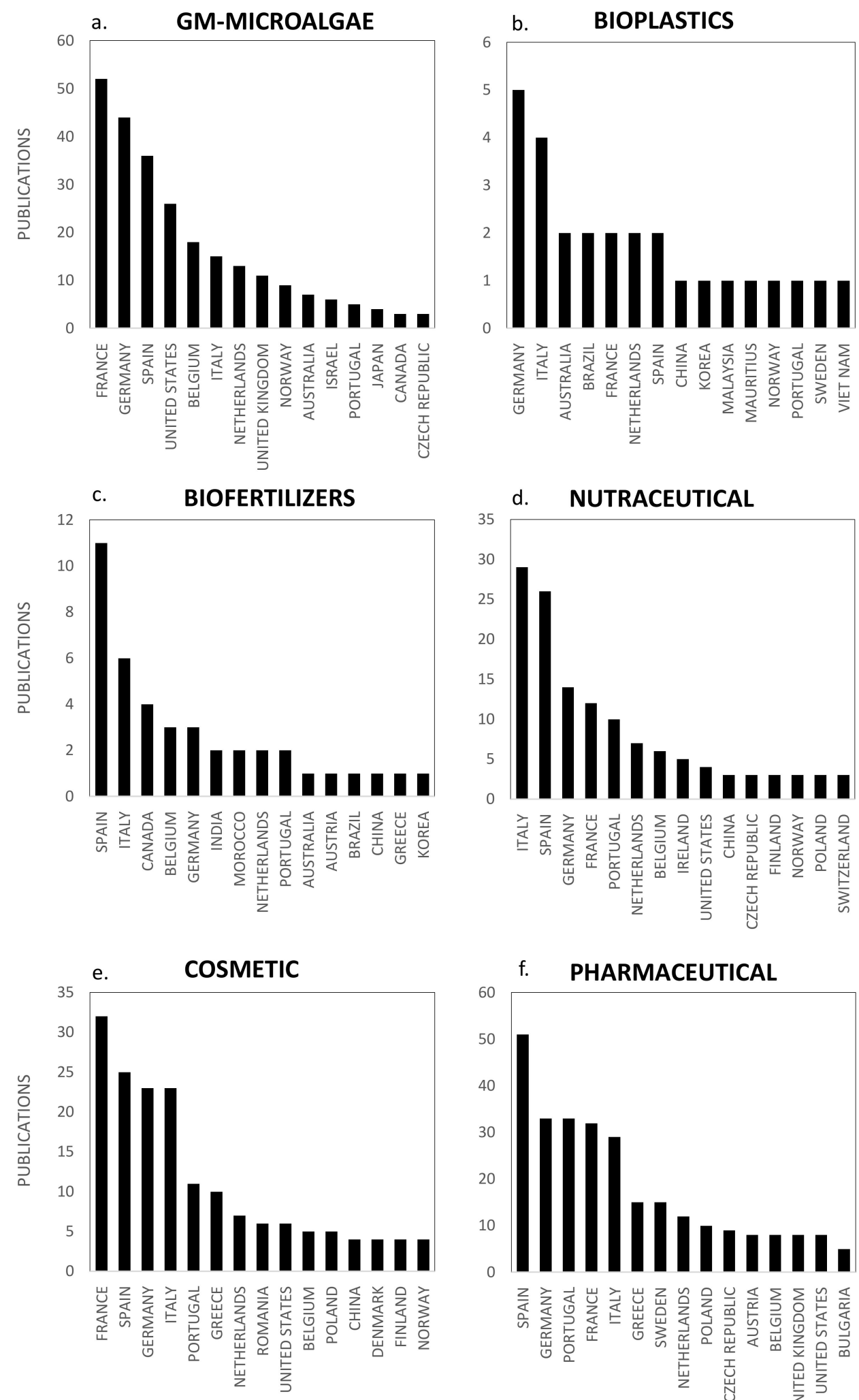

COUNTRIES

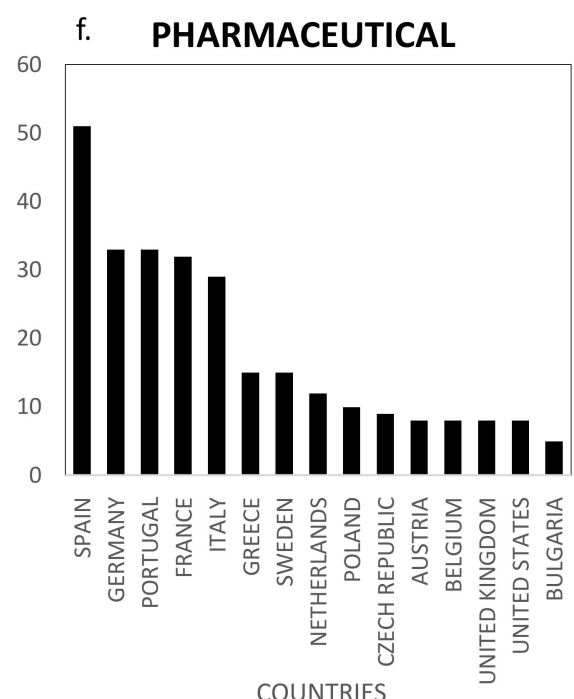

Figure 10. Scientific production by country for the emerging markets of: GM-microalgae (a); bioplastics (b); biofertilizers (c); nutraceutical (d); cosmetic (e); and pharmaceutical (f). 


\section{Material and Methods}

\subsection{Building the Bibliographic Database}

A bibliographic database was built through a literature search performed in February 2019 including all reports published to date. The use of the Scopus database was compulsory to obtain a format compatible with the bibliometric analysis using the Orbit Intellixir ${ }^{\circledR}$ software. The keywords "microalgae" and "phytoplankton" were used to list European publications (including authors from Austria, Belgium, Bulgaria, Cyprus, Croatia, Czech Republic, Denmark, Estonia, Finland, France, Germany, Greece, Hungary, Ireland, Italy, Latvia, Lithuania, Luxembourg, Malta, Netherlands, Poland, Portugal, Romania, Slovakia, Slovenia, Spain, Sweden and UK) including at least one author from Europe. The keywords "microalga(e)" and "phytoplankton" were both selected to include environmental/ecophysiological studies as well as research and development projects dedicated to biotechnological applications for bioremediation, energy, feed, food, cosmetics, pharma, etc. We did not exclude publications dealing with cyanobacteria, considering that the research domains for these prokaryotic organisms were similar to those of microalgae.

\subsection{Bibliometric Analysis: Data Extraction, Analysis, and Graphical Formatting}

The bibliographic database was last updated in February 2019 and it contained 26,137 publications, 46,789 authors, 2393 affiliations and 423,567 concepts. As previously described [11], a "concept" designates a word (or group of words) present in the title, summary or keywords of a publication, that can be extracted and identified using a bibliometric software. The occurrence of a concept is the number of documents containing this concept, and co-occurrence the number of documents linking several concepts. The bibliographic database, including references without duplicates, was imported from Scopus into the Orbit Intellixir ${ }^{\circledR}$ bibliometric software and analyzed to quantify the scientific production in a field of research per year, country. Major and emerging research concepts were graphically represented using the most relevant formats available in the Orbit Intellixir ${ }^{\circledR}$ software. Data were analyzed to highlight the latest trends in research topics, identify the most explored research concepts, and highlight opportunities in the research organizations from Europe. Emerging concepts were defined as concepts that showed the greatest increase in frequency of use in the database over the last two years. A manual selection of emerging concepts was performed, as some of them were relevant for our study (e.g., name of molecules and application domains) while others were less (publisher name, etc.). A growth factor (GF) was calculated to highlight the concepts with the highest emergence over the past two years (2017-2019). GF was calculated as Equation (1).

$$
\mathrm{G}=\frac{P_{2019}-P_{2017}}{P_{2017}}
$$

with $P$ the number of cumulative scientific publications containing the concept at one time.

\section{Conclusions}

This review analyzed 26,137 publications at the European level and gives an in-depth overview of microalgae research with potential markets applications until 2019. The main research concepts contained in the publications, the networks between these concepts, emerging concepts and the annual production of papers were highlighted. The most important scientific works in link with microalgae market applications were dedicated to six major market opportunities for microalgae: the production of biofuels, bioplastics, biofertilizers, nutraceuticals, pharmaceuticals and cosmetics. Research and developments dealing with the production of microalgae-based biofuels have attracted much interest of public and private labs, with more than 1202 papers published in Europe. These works benefited from significant public financial support that allowed to reach high levels of technology readiness. A significant market growth for algal biofuels is expected in the next years, as they hold great promise as a greener and sustainable alternative to fossil and agrofuels, but an improvement 
in their competitiveness is still necessary before large-scale exploitation. Research dedicated to the production of microalgae-based bioplastics or biofertilizers is still in early development, with only about 20 scientific papers published each year in Europe and related markets can be considered as niche markets with a high potential of evolution. It is most likely that these research domains are going to develop quickly in parallel to related markets, according to the high demand for eco-friendly solutions to replace petroleum-based plastics and chemical fertilizers. Last, the development and marketing of microalgae-based nutraceutics, pharmaceuticals and cosmetics has attracted much research interest with more than 600 publications for all these domains in Europe. Although research, developments and markets in these domains are much more advanced for seaweeds, microalgae offer new opportunities for original bioactive molecules and innovative extracts, with the guarantee of a regular supply independent from seasonality and easier management of production, quality and traceability. Finally, two technological domains could have a predominant influence on the marketability and competitivity of microalgae-based molecules, extracts and biomass: the possibility to transform strains to obtain GM-microalgae with high metabolic potential, and innovations in the fields of microalgae growth, harvest and extraction technologies at industrial scale. In this context, Europe, and particularly the European Atlantic Area regions, have many assets to significantly develop the microalgae bioeconomy and counterbalance the current production and market model.

Author Contributions: J.R. and L.P. designed the study. J.R., R.G.d.O.J. and C.F.-G. built the bibliographic database. E.N. allowed access to the Orbit Intellixir ${ }^{\circledR}$ software to perform the bibliometric analysis. J.R. and L.P. performed the bibliometric analysis, interpreted the data and wrote the manuscript. L.P. supervized the whole study and takes responsibility for the integrity of the work. All authors have read and agreed to the published version of the manuscript.

Acknowledgments: This work and J.R.'s post-doctoral grant were funded by the Interreg Atlantic Area European Regional development fund, project Enhance Microalgae EAPA_338/2016. J.R. and L.P. are partners of this project, in charge of Workpackage 4: Gaps and technical barriers to the microalgae sector development in the European Atlantic Area. We are grateful to Annick Salaun from IFREMER, Bibliothèque La Pérouse, Plouzané, for access and formation to the Orbit Intellixir ${ }^{\circledR}$ software to perform the bibliometric analysis and help in graphical formatting of data. We also thank the invited experts that participated in the EnhanceMicroalgae Workpackage 4 Symposium organized in La Rochelle in December 2018, for their important contribution to analyze microalgae research and markets in Europe.

Conflicts of Interest: The authors declare they have no competing interests.

\section{References}

1. Spolaore, P.; Joannis-Cassan, C.; Duran, E.; Isambert, A. Commercial applications of microalgae. J. Biosci. Bioeng. 2006, 101, 87-96. [CrossRef] [PubMed]

2. Garrido-Cardenas, J.A.; Manzano-Agugliaro, F.; Acien-Fernandez, F.G.; Molina-Grima, E. Microalgae research worldwide. Algal Res. 2018, 35, 50-60. [CrossRef]

3. Chisti, Y. Biodiesel from microalgae. Biotechnol. Adv. 2007, 25, 294-306. [CrossRef] [PubMed]

4. Wijffels, R.H.; Barbosa, M.J. An outlook on microalgal biofuels. Science 2010, 329, 796-799. [CrossRef]

5. Chacón-Lee, T.L.; González-Mariño, G.E. Microalgae for "Healthy” Foods-Possibilities and Challenges. Compr. Rev. Food Sci. Food Saf. 2010, 9, 655-675. [CrossRef]

6. Hu, Q.; Sommerfeld, M.; Jarvis, E.; Ghirardi, M.; Posewitz, M.; Seibert, M.; Darzins, A. Microalgal triacylglycerols as feedstocks for biofuel production: Perspectives and advances. Plant. J. Cell Mol. Biol. 2008, 54, 621-639. [CrossRef]

7. Konur, O. The scientometric evaluation of the research on the algae and bio-energy. Appl. Energy 2011, 88, 3532-3540. [CrossRef]

8. Pragya, N.; Pandey, K.K.; Sahoo, P.K. A review on harvesting, oil extraction and biofuels production technologies from microalgae. Renew. Sustain. Energy Rev. 2013, 24, 159-171. [CrossRef]

9. Singh, J.; Gu, S. Commercialization potential of microalgae for biofuels production. Renew. Sustain. Energy Rev. 2010, 14, 2596-2610. [CrossRef] 
10. Rumin, J.; Martins, J.; Cruz, J.; Vasconcelos, V.; Grünewald, C.F.; Flynn, K.J.; Sabin, A.; Paredes, M.; Conde, E.; Vilarino, J.; et al. EnhanceMicroalgae: An European Interregional Project Stimulating Research, Innovation, Industrial Development and Transnational Cooperation within the Atlantic Area Microalgae Sector. J. Oceanogr. Mar. Res. 2018, 6, 1000182. [CrossRef]

11. Rumin, J.; Nicolau, E.; Junior, R.G.d.O.; Fuentes-Grünewald, C.; Flynn, K.J.; Picot, L. A Bibliometric Analysis of Microalgae Research in the World, Europe, and the European Atlantic Area. Mar. Drugs 2020, 18, 79. [CrossRef] [PubMed]

12. Benedetti, M.; Vecchi, V.; Barera, S.; Dall'Osto, L. Biomass from microalgae: The potential of domestication towards sustainable biofactories. Microb. Cell Factories 2018, 17, 173. [CrossRef] [PubMed]

13. Martins, J.; Cruz, D.; Vasconcelos, V. The Nagoya Protocol and Its Implications on the EU Atlantic Area Countries. J. Mar. Sci. Eng. 2020, 8, 92. [CrossRef]

14. Vermuë, M.H.; Eppink, M.H.M.; Wijffels, R.H.; Van Den Berg, C. Multi-Product Microalgae Biorefineries: From Concept Towards Reality. Trends Biotechnol. 2018, 36, 216-227. [CrossRef]

15. Barros, A.I.; Gonçalves, A.L.; Simões, M.; Pires, J.C.M. Harvesting techniques applied to microalgae: A review. Renew. Sustain. Energy Rev. 2015, 41, 1489-1500. [CrossRef]

16. Cancela, A.; Pérez, L.; Febrero, A.; Sánchez, A.; Salgueiro, J.L.; Ortiz, L. Exploitation of Nannochloropsis gaditana biomass for biodiesel and pellet production. Renew. Energy 2019, 133, 725-730. [CrossRef]

17. Castellanos-Estupinan, M.; Sanchez-Galvis, M.; Garcia-Martinez, J.B.; Barajas-Ferreira, C.; Zuorro, A.; Barajas-Solano, A.F. Design of an Electroflotation System for the Concentration and Harvesting of Freshwater Microalgae. Chem. Eng. Trans. 2018, 64,1-6. [CrossRef]

18. Liu, S.; Hajar, H.A.A.; Riefler, G.; Stuart, B.J. Investigation of electrolytic flocculation for microalga Scenedesmus sp. using aluminum and graphite electrodes. RSC Adv. 2018, 8, 38808-38817. [CrossRef]

19. Vandamme, D.; Foubert, I.; Fraeye, I.; Muylaert, K. Influence of organic matter generated by Chlorella vulgaris on five different modes of flocculation. Bioresour. Technol. 2012, 124, 508-511. [CrossRef]

20. Zhu, L.; Li, Z.; Hiltunen, E. Microalgae Chlorella vulgaris biomass harvesting by natural flocculant: Effects on biomass sedimentation, spent medium recycling and lipid extraction. Biotechnol. Biofuels 2018, 11, 183. [CrossRef]

21. Muñoz, R.; Guieysse, B. Algal-bacterial processes for the treatment of hazardous contaminants: A review. Water Res. 2006, 40, 2799-2815. [CrossRef] [PubMed]

22. Vandamme, D.; Foubert, I.; Muylaert, K. Flocculation as a low-cost method for harvesting microalgae for bulk biomass production. Trends Biotechnol. 2013, 31, 233-239. [CrossRef] [PubMed]

23. Salim, S.; Bosma, R.; Vermuë, M.H.; Wijffels, R.H. Harvesting of microalgae by bio-flocculation. J. Appl. Phycol. 2011, 23, 849-855. [CrossRef] [PubMed]

24. Pires, J.C.M.; Alvim-Ferraz, M.C.M.; Martins, F.G.; Simões, M. Carbon dioxide capture from flue gases using microalgae: Engineering aspects and biorefinery concept. Renew. Sustain. Energy Rev. 2012, 16, 3043-3053. [CrossRef]

25. Vandamme, D.; Foubert, I.; Fraeye, I.; Meesschaert, B.; Muylaert, K. Flocculation of Chlorella vulgaris induced by high pH: Role of magnesium and calcium and practical implications. Bioresour. Technol. 2012, 105, 114-119. [CrossRef]

26. Vandamme, D.; Pontes, S.C.V.; Goiris, K.; Foubert, I.; Pinoy, L.J.J.; Muylaert, K. Evaluation of electro-coagulation-flocculation for harvesting marine and freshwater microalgae. Biotechnol. Bioeng. 2011, 108, 2320-2329. [CrossRef]

27. Hejazi, M.A.; Wijffels, R.H. Milking of microalgae. Trends Biotechnol. 2004, 22, 189-194. [CrossRef]

28. Bilad, M.R.; Vandamme, D.; Foubert, I.; Muylaert, K.; Vankelecom, I.F.J. Harvesting microalgal biomass using submerged microfiltration membranes. Bioresour. Technol. 2012, 111, 343-352. [CrossRef]

29. Passos, F.; Uggetti, E.; Carrère, H.; Ferrer, I. Pretreatment of microalgae to improve biogas production: A review. Bioresour. Technol. 2014, 172, 403-412. [CrossRef]

30. Şirin, S.; Trobajo, R.; Ibanez, C.; Salvadó, J. Harvesting the microalgae Phaeodactylum tricornutum with polyaluminum chloride, aluminium sulphate, chitosan and alkalinity-induced flocculation. J. Appl. Phycol. 2012, 24, 1067-1080. [CrossRef]

31. Vrieling, E.G.; Beelen, T.P.M.; van Santen, R.A.; Gieskes, W.W.C. Diatom silicon biomineralization as an inspirational source of new approaches to silica production. Prog. Ind. Microbiol. 1999, 35, 39-51. 
32. Roy, S.; Chanut, J.P.; Gosselin, M.; Sime-Ngando, T. Characterization of phytoplankton communities in the lower St. Lawrence Estuary using HPLC-detected pigments and cell microscopy. Mar. Ecol. Prog. Ser. 1996, 142, 55-73. [CrossRef]

33. Forest, A.; Tremblay, J.-É.; Gratton, Y.; Martin, J.; Gagnon, J.; Darnis, G.; Sampei, M.; Fortier, L.; Ardyna, M.; Gosselin, M.; et al. Biogenic carbon flows through the planktonic food web of the Amundsen Gulf (Arctic Ocean): A synthesis of field measurements and inverse modeling analyses. Prog. Oceanogr. 2011, 91, 410-436. [CrossRef]

34. Gerardo, M.L.; Zanain, M.A.; Lovitt, R.W. Pilot-scale cross-flow microfiltration of Chlorella minutissima: A theoretical assessment of the operational parameters on energy consumption. Chem. Eng. J. 2015, 280, 505-513. [CrossRef]

35. Adam, F.; Abert-Vian, M.; Peltier, G.; Chemat, F. "Solvent-free" ultrasound-assisted extraction of lipids from fresh microalgae cells: A green, clean and scalable process. Bioresour. Technol. 2012, 114, 457-465. [CrossRef]

36. Delrue, F.; Setier, P.-A.; Sahut, C.; Cournac, L.; Roubaud, A.; Peltier, G.; Froment, A.-K. An economic, sustainability, and energetic model of biodiesel production from microalgae. Bioresour. Technol. 2012, 111, 191-200. [CrossRef]

37. Converti, A.; Casazza, A.A.; Ortiz, E.Y.; Perego, P.; Del Borghi, M. Effect of temperature and nitrogen concentration on the growth and lipid content of Nannochloropsis oculata and Chlorella vulgaris for biodiesel production. Chem. Eng. Process. Process. Intensif. 2009, 48, 1146-1151. [CrossRef]

38. Cravotto, G.; Boffa, L.; Mantegna, S.; Perego, P.; Avogadro, M.; Cintas, P. Improved extraction of vegetable oils under high-intensity ultrasound and/or microwaves. Ultrason. Sonochem. 2008, 15, 898-902. [CrossRef]

39. Garcia Alba, L.; Torri, C.; Samorì, C.; van der Spek, J.; Fabbri, D.; Kersten, S.R.A.; Brilman, D.W.F. (Wim) Hydrothermal Treatment (HTT) of Microalgae: Evaluation of the Process As Conversion Method in an Algae Biorefinery Concept. Energy Fuels 2012, 26, 642-657. [CrossRef]

40. Plaza, M.; Herrero, M.; Cifuentes, A.; Ibáñez, E. Innovative Natural Functional Ingredients from Microalgae. J. Agric. Food Chem. 2009, 57, 7159-7170. [CrossRef]

41. Plaza, M.; Santoyo, S.; Jaime, L.; García-Blairsy Reina, G.; Herrero, M.; Señoráns, F.J.; Ibáñez, E. Screening for bioactive compounds from algae. J. Pharm. Biomed. Anal. 2010, 51, 450-455. [CrossRef] [PubMed]

42. Medina, A.R.; Grima, E.M.; Giménez, A.G.; González, M.J.I. Downstream processing of algal polyunsaturated fatty acids. Biotechnol. Adv. 1998, 16, 517-580. [CrossRef]

43. Fernández-Sevilla, J.M.; Acién Fernández, F.G.; Molina Grima, E. Biotechnological production of lutein and its applications. Appl. Microbiol. Biotechnol. 2010, 86, 27-40. [CrossRef] [PubMed]

44. Herrero, M.; Martín-Álvarez, P.J.; Señoráns, F.J.; Cifuentes, A.; Ibáñez, E. Optimization of accelerated solvent extraction of antioxidants from Spirulina platensis microalga. Food Chem. 2005, 93, 417-423. [CrossRef]

45. Fajardo, A.R.; Cerdán, L.E.; Medina, A.R.; Fernández, F.G.A.; Moreno, P.A.G.; Grima, E.M. Lipid extraction from the microalga Phaeodactylum tricornutum. Eur. J. Lipid Sci. Technol. 2007, 109, 120-126. [CrossRef]

46. Gregor, J.; Maršálek, B. Freshwater phytoplankton quantification by chlorophyll a: A comparative study of in vitro, in vivo and in situ methods. Water Res. 2004, 38, 517-522. [CrossRef]

47. Godfray, H.C.J.; Beddington, J.R.; Crute, I.R.; Haddad, L.; Lawrence, D.; Muir, J.F.; Pretty, J.; Robinson, S.; Thomas, S.M.; Toulmin, C. Food Security: The Challenge of Feeding 9 Billion People. Science 2010, 327, 812-818. [CrossRef]

48. Zhu, L. Microalgal culture strategies for biofuel production: A review. Biofuels Bioprod. Biorefining 2015, 9 , 801-814. [CrossRef]

49. Rawat, I.; Ranjith Kumar, R.; Mutanda, T.; Bux, F. Dual role of microalgae: Phycoremediation of domestic wastewater and biomass production for sustainable biofuels production. Appl. Energy 2011, 88, 3411-3424. [CrossRef]

50. Khan, M.I.; Shin, J.H.; Kim, J.D. The promising future of microalgae: Current status, challenges, and optimization of a sustainable and renewable industry for biofuels, feed, and other products. Microb. Cell Factories 2018, 17, 36. [CrossRef]

51. Raheem, A.; Prinsen, P.; Vuppaladadiyam, A.K.; Zhao, M.; Luque, R. A review on sustainable microalgae based biofuel and bioenergy production: Recent developments. J. Clean. Prod. 2018, 181, 42-59. [CrossRef]

52. Mata, T.M.; Martins, A.A.; Caetano, N.S. Microalgae for biodiesel production and other applications: A review. Renew. Sustain. Energy Rev. 2010, 14, 217-232. [CrossRef] 
53. Vanthoor-Koopmans, M.; Wijffels, R.H.; Barbosa, M.J.; Eppink, M.H.M. Biorefinery of microalgae for food and fuel. Bioresour. Technol. 2013, 135, 142-149. [CrossRef]

54. Formighieri, C.; Franck, F.; Bassi, R. Regulation of the pigment optical density of an algal cell: Filling the gap between photosynthetic productivity in the laboratory and in mass culture. J. Biotechnol. 2012, 162, 115-123. [CrossRef]

55. Melis, A. Solar energy conversion efficiencies in photosynthesis: Minimizing the chlorophyll antennae to maximize efficiency. Plant. Sci. 2009, 177, 272-280. [CrossRef]

56. Rodolfi, L.; Chini Zittelli, G.; Bassi, N.; Padovani, G.; Biondi, N.; Bonini, G. Microalgae for oil: Strain selection, induction of lipid synthesis and outdoor mass cultivation in a low-cost photobioreactor. Biotechnol. Bioeng. 2009, 102, 100-112. [CrossRef]

57. Markou, G.; Vandamme, D.; Muylaert, K. Microalgal and cyanobacterial cultivation: The supply of nutrients. Water Res. 2014, 65, 186-202. [CrossRef] [PubMed]

58. Barbera, E.; Bertucco, A.; Kumar, S. Nutrients recovery and recycling in algae processing for biofuels production. Renew. Sustain. Energy Rev. 2018, 90, 28-42. [CrossRef]

59. Quiroz Arita, C.E.; Peebles, C.; Bradley, T.H. Scalability of combining microalgae-based biofuels with wastewater facilities: A review. Algal Res. 2015, 9, 160-169. [CrossRef]

60. Komolafe, O.; Velasquez Orta, S.B.; Monje-Ramirez, I.; Noguez, I.Y.; Harvey, A.P.; Orta Ledesma, M.T. Biodiesel production from indigenous microalgae grown in wastewater. Bioresour. Technol. 2014, 154, $297-304$. [CrossRef]

61. Cho, S.; Luong, T.T.; Lee, D.; Oh, Y.-K.; Lee, T. Reuse of effluent water from a municipal wastewater treatment plant in microalgae cultivation for biofuel production. Bioresour. Technol. 2011, 102, 8639-8645. [CrossRef] [PubMed]

62. Silkina, A.; Ginnever, N.E.; Fernandes, F.; Fuentes-Grünewald, C. Large-Scale Waste Bio-Remediation Using Microalgae Cultivation as a Platform. Energies 2019, 12, 2772. [CrossRef]

63. Mayhead, E.; Silkina, A.; Llewellyn, C.A.; Fuentes-Grünewald, C. Comparing Nutrient Removal from Membrane Filtered and Unfiltered Domestic Wastewater Using Chlorella vulgaris. Biology 2018, 7, 12. [CrossRef] [PubMed]

64. Gendy, T.S.; El-Temtamy, S.A. Commercialization potential aspects of microalgae for biofuel production: An overview. Egypt. J. Pet. 2013, 22, 43-51. [CrossRef]

65. Flynn, K.J. Enhancing Microalgal Production-Constructing Decision Support Tools Using System Dynamics Modelling. Swansea University, 2020. Available online: https://www.enhancemicroalgae.eu/decision-supporttool/ (accessed on 28 April 2020).

66. Ueda, R.; Hirayama, S.; Sugata, K.; Nakayama, H. Process for the Production of Ethanol from Microalgae. U.S. Patent US5578472A, 26 November 1996.

67. Karan, H.; Funk, C.; Grabert, M.; Oey, M.; Hankamer, B. Green Bioplastics as Part of a Circular Bioeconomy. Trends Plant. Sci. 2019, 24, 237-249. [CrossRef]

68. Prata, J.C.; da Costa, J.P.; Lopes, I.; Duarte, A.C.; Rocha-Santos, T. Effects of microplastics on microalgae populations: A critical review. Sci. Total Environ. 2019, 665, 400-405. [CrossRef]

69. Zhang, C.; Chen, X.; Wang, J.; LijuTan, L. Toxic effects of microplastic on marine microalgae Skeletonema costatum: Interactions between microplastic and algae. Environ. Pollut. 2017, 220, 1282-1288. [CrossRef]

70. Rahman, A.; Miller, C.D. Chapter 6-Microalgae as a Source of Bioplastics. In Algal Green Chemistry; Rastogi, R.P., Madamwar, D., Pandey, A., Eds.; Elsevier: Amsterdam, The Netherlands, 2017; pp. 121-138. ISBN 978-0-444-63784-0.

71. Stiles, W.A.V.; Styles, D.; Chapman, S.P.; Esteves, S.; Bywater, A.; Melville, L.; Silkina, A.; Lupatsch, I.; Fuentes Grünewald, C.; Lovitt, R.; et al. Using microalgae in the circular economy to valorise anaerobic digestate: Challenges and opportunities. Bioresour. Technol. 2018, 267, 732-742. [CrossRef]

72. Ball, S.G.; Dirick, L.; Decq, A.; Martiat, J.-C.; Matagne, R.F. Physiology of starch storage in the monocellular alga Chlamydomonas reinhardtii. Plant. Sci. 1990, 66, 1-9. [CrossRef]

73. Jerez, C.G.; Malapascua, J.R.; Sergejevová, M.; Figueroa, F.L.; Masojídek, J. Effect of Nutrient Starvation under High Irradiance on Lipid and Starch Accumulation in Chlorella fusca (Chlorophyta). Mar. Biotechnol. 2016, 18, 24-36. [CrossRef] 
74. Li, Y.; Horsman, M.; Wang, B.; Wu, N.; Lan, C.Q. Effects of nitrogen sources on cell growth and lipid accumulation of green alga Neochloris oleoabundans. Appl. Microbiol. Biotechnol. 2008, 81, 629-636. [CrossRef] [PubMed]

75. Cheng, Y.-S.; Labavitch, J.M.; VanderGheynst, J.S. Elevated CO2 concentration impacts cell wall polysaccharide composition of green microalgae of the genus Chlorella. Lett. Appl. Microbiol. 2015, 60, 1-7. [CrossRef] [PubMed]

76. Yao, C.; Ai, J.; Cao, X.; Xue, S.; Zhang, W. Enhancing starch production of a marine green microalga Tetraselmis subcordiformis through nutrient limitation. Bioresour. Technol. 2012, 118, 438-444. [CrossRef] [PubMed]

77. Fuentes-Grünewald, C.; Garcés, E.; Alacid, E.; Sampedro, N.; Rossi, S.; Camp, J. Improvement of lipid production in the marine strains Alexandrium minutum and Heterosigma akashiwo by utilizing abiotic parameters. J. Ind. Microbiol. Biotechnol. 2012, 39, 207-216. [CrossRef]

78. Markou, G.; Angelidaki, I.; Georgakakis, D. Microalgal carbohydrates: An overview of the factors influencing carbohydrates production, and of main bioconversion technologies for production of biofuels. Appl. Microbiol. Biotechnol. 2012, 96, 631-645. [CrossRef] [PubMed]

79. Kobayashi, M.; Kurimura, Y.; Sakamoto, Y.; Tsuji, Y. Selective extraction of astaxanthin and chlorophyll from the green alga Haematococcus pluvialis. Biotechnol. Tech. 1997, 11, 657-660. [CrossRef]

80. Mathiot, C.; Ponge, P.; Gallard, B.; Sassi, J.-F.; Delrue, F.; Le Moigne, N. Microalgae starch-based bioplastics: Screening of ten strains and plasticization of unfractionated microalgae by extrusion. Carbohydr. Polym. 2019, 208, 142-151. [CrossRef]

81. Kawalekar, J.S. Role of biofertilizers and biopesticides for sustainable agriculture. J. Bio Innov. 2013, $2,73-78$.

82. Gouveia, L.; Graça, S.; Sousa, C.; Ambrosano, L.; Ribeiro, B.; Botrel, E.P.; Neto, P.C.; Ferreira, A.F.; Silva, C.M. Microalgae biomass production using wastewater: Treatment and costs: Scale-up considerations. Algal Res. 2016, 16, 167-176. [CrossRef]

83. Win, T.T.; Barone, G.D.; Secundo, F.; Fu, P. Algal Biofertilizers and Plant Growth Stimulants for Sustainable Agriculture. Ind. Biotechnol. 2018, 14, 203-211. [CrossRef]

84. Coppens, J.; Grunert, O.; Van Den Hende, S.; Vanhoutte, I.; Boon, N.; Haesaert, G.; De Gelder, L. The use of microalgae as a high-value organic slow-release fertilizer results in tomatoes with increased carotenoid and sugar levels. J. Appl. Phycol. 2016, 28, 2367-2377. [CrossRef]

85. Garcia-Gonzalez, J.; Sommerfeld, M. Biofertilizer and biostimulant properties of the microalga Acutodesmus dimorphus. J. Appl. Phycol. 2016, 28, 1051-1061. [CrossRef] [PubMed]

86. García, J.L.; de Vicente, M.; Galán, B. Microalgae, old sustainable food and fashion nutraceuticals. Microb. Biotechnol. 2017, 10, 1017-1024. [CrossRef]

87. Chew, K.W.; Yap, J.Y.; Show, P.L.; Suan, N.H.; Juan, J.C.; Ling, T.C.; Lee, D.-J.; Chang, J.-S. Microalgae biorefinery: High value products perspectives. Bioresour. Technol. 2017, 229, 53-62. [CrossRef] [PubMed]

88. Odjadjare, E.C.; Mutanda, T.; Olaniran, A.O. Potential biotechnological application of microalgae: A critical review. Crit. Rev. Biotechnol. 2017, 37, 37-52. [CrossRef] [PubMed]

89. Bleakley, S.; Hayes, M. Algal Proteins: Extraction, Application, and Challenges Concerning Production. Foods Basel Switz. 2017, 6, 33. [CrossRef] [PubMed]

90. Liu, L.; Pohnert, G.; Wei, D. Extracellular Metabolites from Industrial Microalgae and Their Biotechnological Potential. Mar. Drugs 2016, 14, 191. [CrossRef]

91. Yaakob, Z.; Ali, E.; Zainal, A.; Mohamad, M.; Takriff, M.S. An overview: Biomolecules from microalgae for animal feed and aquaculture. J. Biol. Res. Thessalon. Greece 2014, 21, 6. [CrossRef]

92. Bilal, M.; Rasheed, T.; Ahmed, I.; Iqbal, H.M.N. High-value compounds from microalgae with industrial exploitability-A review. Front. Biosci. Sch. Ed. 2017, 9, 319-342. [CrossRef]

93. Nicoletti, M. Microalgae Nutraceuticals. Foods 2016, 5, 54. [CrossRef]

94. Wells, M.L.; Potin, P.; Craigie, J.S.; Raven, J.A.; Merchant, S.S.; Helliwell, K.E.; Smith, A.G.; Camire, M.E.; Brawley, S.H. Algae as nutritional and functional food sources: Revisiting our understanding. J. Appl. Phycol. 2017, 29, 949-982. [CrossRef] [PubMed]

95. Yan, N.; Fan, C.; Chen, Y.; Hu, Z. The Potential for Microalgae as Bioreactors to Produce Pharmaceuticals. Int. J. Mol. Sci. 2016, 17, 962. [CrossRef] [PubMed] 
96. Fuentes-Grünewald, C.; Bayliss, C.; Zanain, M.; Pooley, C.; Scolamacchia, M.; Silkina, A. Evaluation of batch and semi-continuous culture of Porphyridium purpureum in a photobioreactor in high latitudes using Fourier Transform Infrared spectroscopy for monitoring biomass composition and metabolites production. Bioresour. Technol. 2015, 189, 357-363. [CrossRef] [PubMed]

97. Sonani, R.R.; Rastogi, R.P.; Patel, R.; Madamwar, D. Recent advances in production, purification and applications of phycobiliproteins. World J. Biol. Chem. 2016, 7, 100-109. [CrossRef] [PubMed]

98. Luo, X.; Su, P.; Zhang, W. Advances in Microalgae-Derived Phytosterols for Functional Food and Pharmaceutical Applications. Mar. Drugs 2015, 13, 4231-4254. [CrossRef]

99. De Morais, M.G.; Vaz, B.D.S.; de Morais, E.G.; Costa, J.A.V. Biologically Active Metabolites Synthesized by Microalgae. BioMed Res. Int. 2015, 2015, 835761. [CrossRef]

100. Borowitzka, M.A. Microalgae as sources of pharmaceuticals and other biologically active compounds. J. Appl. Phycol. 1995, 7, 3-15. [CrossRef]

101. Mimouni, V.; Ulmann, L.; Pasquet, V.; Mathieu, M.; Picot, L.; Bougaran, G.; Cadoret, J.-P.; Morant-Manceau, A.; Schoefs, B. The potential of microalgae for the production of bioactive molecules of pharmaceutical interest. Curr. Pharm. Biotechnol. 2012, 13, 2733-2750. [CrossRef]

102. Bishop, W.M.; Zubeck, H.M. Evaluation of Microalgae for use as Nutraceuticals and Nutritional Supplements. J. Nutr. Food Sci. 2012, 2, 5. [CrossRef]

103. Gargouch, N.; Karkouch, I.; Elleuch, J.; Elkahoui, S.; Michaud, P.; Abdelkafi, S.; Laroche, C.; Fendri, I. Enhanced B-phycoerythrin production by the red microalga Porphyridium marinum: A powerful agent in industrial applications. Int. J. Biol. Macromol. 2018, 120, 2106-2114. [CrossRef]

104. García-López, D.A.; Olguín, E.J.; González-Portela, R.E.; Sánchez-Galván, G.; De Philippis, R.; Lovitt, R.W.; Llewellyn, C.A.; Fuentes-Grünewald, C.; Parra Saldívar, R. A novel two-phase bioprocess for the production of Arthrospira (Spirulina) maxima LJGR1 at pilot plant scale during different seasons and for phycocyanin induction under controlled conditions. Bioresour. Technol. 2019, 122548. [CrossRef] [PubMed]

105. Sosa-Hernández, J.E.; Rodas-Zuluaga, L.I.; Castillo-Zacarías, C.; Rostro-Alanís, M.; de la Cruz, R.; Carrillo-Nieves, D.; Salinas-Salazar, C.; Fuentes Grunewald, C.; Llewellyn, C.A.; Olguín, E.J.; et al. Light Intensity and Nitrogen Concentration Impact on the Biomass and Phycoerythrin Production by Porphyridium purpureum. Mar. Drugs 2019, 17, 460. [CrossRef] [PubMed]

106. Kim, S.-K. Marine Pharmacognosy: Trends and Applications; CRC Press: Boca Raton, FL, USA, 2012; ISBN 978-1-4398-9229-9.

107. Mourelle, M.L.; Gómez, C.P.; Legido, J.L. The Potential Use of Marine Microalgae and Cyanobacteria in Cosmetics and Thalassotherapy. Cosmetics 2017, 4, 46. [CrossRef]

108. Heydarizadeh, P.; Poirier, I.; Loizeau, D.; Ulmann, L.; Mimouni, V.; Schoefs, B.; Bertrand, M. Plastids of Marine Phytoplankton Produce Bioactive Pigments and Lipids. Mar. Drugs 2013, 11, 3425-3471. [CrossRef] [PubMed]

109. Bermejo, R.; Acién, F.G.; Ibáñez, M.J.; Fernández, J.M.; Molina, E.; Alvarez-Pez, J.M. Preparative purification of B-phycoerythrin from the microalga Porphyridium cruentum by expanded-bed adsorption chromatography. J. Chromatogr. B Analyt. Technol. Biomed. Life Sci. 2003, 790, 317-325. [CrossRef]

110. Koller, M.; Muhr, A.; Braunegg, G. Microalgae as versatile cellular factories for valued products. Algal Res. 2014, 6, 52-63. [CrossRef]

111. Jain, R.; Raghukumar, S.; Tharanathan, R.; Bhosle, N.B. Extracellular polysaccharide production by thraustochytrid protists. Mar. Biotechnol. 2005, 7, 184-192. [CrossRef]

112. De Jesus Raposo, M.F.; de Morais, A.M.B.; de Morais, R.M.S.C. Marine polysaccharides from algae with potential biomedical applications. Mar. Drugs 2015, 13, 2967-3028. [CrossRef]

113. Hashtroudi, M.S.; Shariatmadari, Z.; Riahi, H.; Ghassempour, A. Analysis of Anabaena vaginicola and Nostoc calcicola from Northern Iran, as rich sources of major carotenoids. Food Chem. 2013, 136, 1148-1153. [CrossRef]

114. Singh, P.; Rani, B.; Chauhan, A.K.; Maheshwari, R. Lycopene's antioxydant activity in cosmetics meadow. Int. Res. J. Pharm. 2012, 3, 2.

115. Lu, Y.; Xu, J. Phytohormones in microalgae: A new opportunity for microalgal biotechnology? Trends Plant. Sci. 2015, 20, 273-282. [CrossRef] [PubMed] 
116. Michelet, J.F.; Olive, C.; Rieux, E.; Fagot, D.; Simonetti, L.; Galey, J.B.; Dalko-Csiba, M.; Bernard, B.A.; Pereira, R. The anti-ageing potential of a new jasmonic acid derivative (LR2412): In vitro evaluation using reconstructed epidermis Episkin ${ }^{\mathrm{TM}}$. Exp. Dermatol. 2012, 21, 398-400. [CrossRef] [PubMed]

117. Singh, R.; Parihar, P.; Singh, M.; Bajguz, A.; Kumar, J.; Singh, S.; Singh, V.P.; Prasad, S.M. Uncovering Potential Applications of Cyanobacteria and Algal Metabolites in Biology, Agriculture and Medicine: Current Status and Future Prospects. Front. Microbiol. 2017, 8, 515. [CrossRef] [PubMed]

(c)

(C) 2020 by the authors. Licensee MDPI, Basel, Switzerland. This article is an open access article distributed under the terms and conditions of the Creative Commons Attribution (CC BY) license (http://creativecommons.org/licenses/by/4.0/). 